\title{
Future changes in tropical cyclone activity in the North Indian Ocean projected by high-resolution MRI-AGCMs
}

\author{
Hiroyuki Murakami • Masato Sugi • \\ Akio Kitoh
}

Received: 8 February 2012/ Accepted: 21 May 2012/Published online: 8 June 2012

(C) The Author(s) 2012. This article is published with open access at Springerlink.com

\begin{abstract}
New and previous versions of the high-resolution 20- and 60-km-mesh Meteorological Research Institute atmospheric general circulation models are used to investigate potential future changes in tropical cyclone (TC) activity in the North Indian Ocean (NIO). Fifteen ensemble experiments are performed under the International Panel on Climate Change A1B scenario. Most of the ensemble future (2075-2099) experiments do not project significant future changes in the basin-scale TC genesis number; however, they commonly show a substantial increase (by $46 \%$ ) in TC frequency over the Arabian Sea and a decrease (by $31 \%$ ) in the Bay of Bengal. Projected future changes in TC genesis frequency show a marked seasonal variation in the NIO: a significant and robust reduction during the pre-monsoon season, an increase during the peak-monsoon season, and a westward shift during the post-monsoon season. Several large-scale thermodynamic and dynamical parameters are analysed to elucidate the physical mechanism responsible for the future changes in TC activity; this analysis reveals a seasonal
\end{abstract}

H. Murakami · M. Sugi

Japan Agency for Marine-Earth Science and Technology

(JAMSTEC), Meteorological Research Institute, Tsukuba,

Ibaraki, Japan

Present Address:

H. Murakami $(\bowtie)$

International Pacific Research Center, School of Ocean and

Earth Science and Technology, University of Hawaii at Manoa,

1680 East West Road, POST Bldg. 401, Honolulu,

HI 96822, USA

e-mail: hir.murakami@gmail.com

\section{A. Kitoh}

Meteorological Research Institute, Tsukuba, Ibaraki, Japan dependence of the relative contribution of these parameters to the projected future changes in TC genesis frequency.

Keywords Tropical cyclone - Global warming · High-resolution model · North Indian Ocean

\section{Introduction}

A tropical cyclone (TC) over the North Indian Ocean (NIO) is designated a "cyclone" when its maximum surface wind exceeds $34 \mathrm{kt}$. According to observations based on the International Best Tracks Archive for Climate Stewardship (IBTrACS) dataset (Knapp et al. 2010), the mean annual number of named storms [wind speeds $\geq$ $34 \mathrm{kts}\left(17.5 \mathrm{~m} \mathrm{~s}^{-1}\right)$ ] in the NIO during 1980-2009 was 6.3, which is just $7.3 \%$ of the global mean of 86.5 (Diamond and Trewin 2011). Given the small sample size and the limited period of reliable satellite-based data, there is little information on the present-day TC climatology and on the effect of global warming on TC activity over NIO (e.g., Landsea et al. 2006).

Recent TC activity in the NIO has received great attention from the public and from the research community. For example, Cyclone Nargis, which formed in the Bay of Bengal (hereafter referred to as BOB) in May 2008, made landfall in Myanmar and caused catastrophic damage. Cyclone Gonu, which formed in the Arabian Sea (hereafter referred to as ARB) in June 2007, was the first Category 5 cyclone in the region and caused damage in Oman, resulting in the nation's worst natural disaster. Evan and Camargo (2011) reported an apparent increase in TC days per year (the number of days that a tropical cyclone is present in the basin) in the ARB over the period 1992-2008 compared with 1979-1991. This trend appears to be related 
to an increase in TC genesis number in the later period (1.8 TCs per year) compared with the earlier period $(0.8 \mathrm{TCs}$ per year). The authors also reported that accumulated cyclone energy (ACE; Bell 2003), which is the sum of the square of each storm's maximum sustained wind speed, increased by roughly a factor of four over the period 1998-2008 compared with 1979-1997, reflecting a recent increase in extremely intense TCs in the ARB. These recent extremely intense TCs have stimulated public interest in the relationship between TCs and global warming, because both theory (Emanuel 1987) and modelling studies (Knutson et al. 2010) suggest that TC intensity could increase in a warming climate (Solomon et al. 2007).

Future change in TCs in the NIO has received little attention, mainly because state-of-the-art models remain unable to reproduce reasonable present-day TC climatology in this region (e.g., Zhao and Held 2012). The small TC sample over the NIO also requires a longer simulation period as well as a number of ensemble experiments to detect a signal of climate change, which requires vast computational resources for high-resolution simulations. Furthermore, projected regional changes in TCs are inconsistent among projections using state-of-the-art models (Knutson et al. 2010). Knutson et al. (2010) reported that fractional changes in TC genesis frequency in the NIO vary from -52 to $+79 \%$ compared with their present-day control simulations (table s1 in their study). Moreover, among their 19 experiments, 5 show increases and 14 show decreases. This inconsistency among the projections arises from various factors, as documented by Murakami et al. (2012a). Because a TC is an aggregation of convective activity, cumulus parameterisation scheme in a model appears to be one of the major sources of uncertainty. Some studies have also addressed uncertainties due to variations in assumed future changes in SST (Emanuel 2008; Sugi et al. 2009; Zhao et al. 2009), resulting in diverse future changes in TC number in a specific oceanbasin scale.

The main aim of the study is to examine potential future changes in TC activity in the NIO and to identify physical mechanisms behind the changes which have received little attention in previous studies. In order to address the uncertainties in future projections, we conduct ensemble projections using two versions of $20-$ and $60-\mathrm{km}$-mesh high-resolution atmospheric models that consider differences among simulation settings in the spatial patterns of tropical SST changes and model physics, particularly the cumulus parameterisation scheme. It is important to derive robust signals across any choices of experimental settings. Murakami et al. (2012a) examined the sensitivity of future TC projections with various cumulus parameterisation schemes and various future SST patterns. In the present study, we extend this methodology by adding more ensemble members using different versions of the MRIAGCM.

The remainder of this paper is organised as follows. Section 2 briefly describes the models, experimental design, and analysis methods. Section 3 presents an evaluation of the present-day simulations, and Sect. 4 presents the results of future projections. Section 5 discusses the physical mechanisms that underlie the projected future changes. Finally, a summary is provided in Sect. 6 .

\section{Methods}

\subsection{Models}

The model used in this study is the Meteorological Research Institute Atmospheric General Circulation Model (MRI-AGCM) version 3.1 (MRI-AGCM3.1; Mizuta et al. 2006) and 3.2 (MRI-AGCM3.2; Mizuta et al. 2012). The model simulations are run at a horizontal resolution of $\mathrm{T}_{\mathrm{L}} 959$ (equivalent to $\left.20-\mathrm{km}-\mathrm{mesh}\right)$ and $\mathrm{T}_{\mathrm{L}} 319(60-\mathrm{km}$ mesh). The model is equipped with multiple cumulus convection schemes, which can be easily switched. In this study, three cumulus convection schemes are used to develop the multi-physics ensemble simulations: a prognostic Arakawa-Schubert (AS) cumulus convection scheme (Arakawa and Schubert 1974; Randall and Pan 1993); a new cumulus convection scheme, called the "Yoshimura scheme (YS)" after a model developer at the MRI (Yukimoto et al. 2011; Mizuta et al. 2012); and a Kain-Fritsch (KF) convection scheme (Kain and Fritsch 1990, 1993).

\subsection{Boundary conditions}

The simulation settings and observational datasets are identical to those used by Murakami et al. (2012a). A socalled "time-slice" method (Bengtsson et al. 1996) is applied, in which the high-resolution AGCM is forced by setting the lower boundary conditions to prescribed SSTs. The control realisations are prescribed as observed monthly mean SSTs and sea ice concentrations during 1979-2003 according to the Hadley Centre Global Sea Ice and Sea Surface Temperature dataset (HadISST1; Rayner et al. 2003).

The targeted projection window for the future climate is the last quarter of the twenty-first century (2075-2099). For the SST-ensemble projections, four different projections of future SSTs are prescribed, each with a different spatial SST anomaly pattern. One of these patterns is the multimodel ensemble mean SST computed from future projections by the 18 CMIP3 models under the Special Report on 
(a) CMIP3 Mean SST (CO)

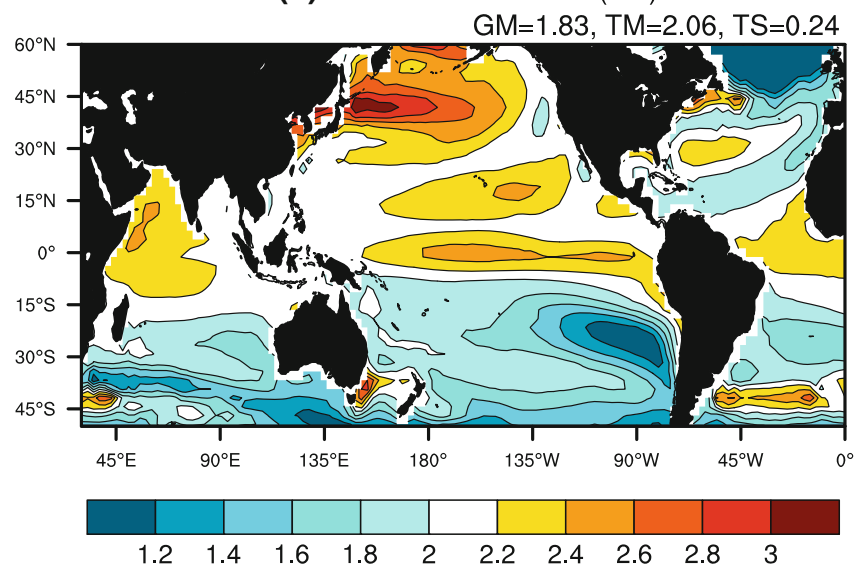

(c) Cluster2 SST (C2)

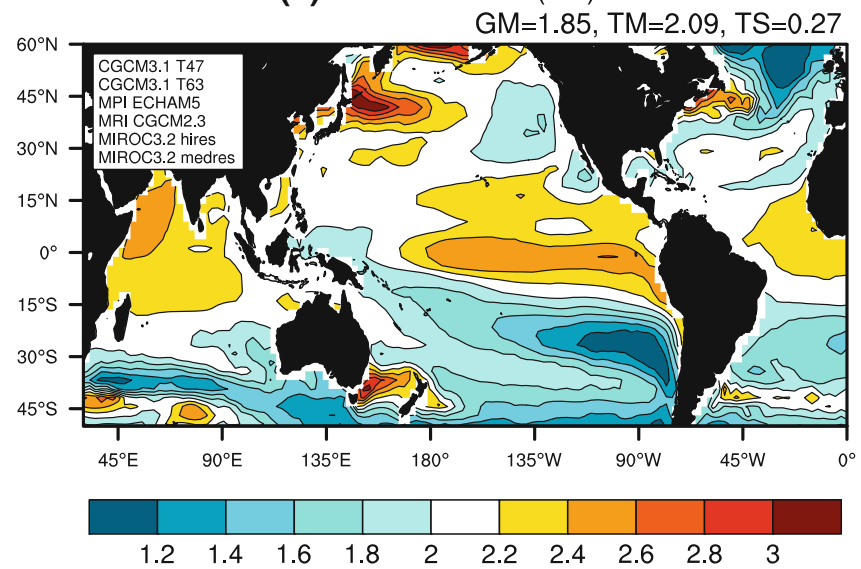

Fig. 1 Annual means of prescribed future changes in sea surface temperature (SST) $\left[{ }^{\circ} \mathrm{C}\right]$. a Ensemble mean of $18 \mathrm{CMIP} 3$ models $(\mathrm{C} 0)$. b-d Changes in SST classified using a cluster analysis (C1-C3). The numbers at the top right of each panel show the global mean SST change

Emission Scenarios (SRES) A1B scenario (hereafter referred to as C0 SST; Solomon et al. 2007). The other three patterns are created using a cluster analysis, in which normalised tropical SST anomalies derived from the 18 CMIP3 models are grouped to avoid the subjective selection of a single model (hereafter referred to as $\mathrm{C} 1-\mathrm{C} 3$ SSTs; Murakami et al. 2012a).

Figure 1 shows all four prescribed future changes in annual-mean SST. The grouped three cluster SSTs are shown in Fig. 1b-d. C1 (Fig. 1b) shows less spatial variation in warming over the tropics relative to $\mathrm{C} 0$ and the other clusters. C2 (Fig. 1c) is similar to $\mathrm{C} 0$, but with greater warming in the ARB than the other prescribed SSTs. C3 (Fig. 1d) shows the largest spatial variation in the tropics among the prescribed SSTs; however, it shows similar warming to the CMIP3 ensemble mean in the NIO. The cluster procedure was originally developed for the alltropical SST anomaly distribution, in which mean future change in SST is normalised by dividing by the tropical (b) Cluster1 SST (C1)

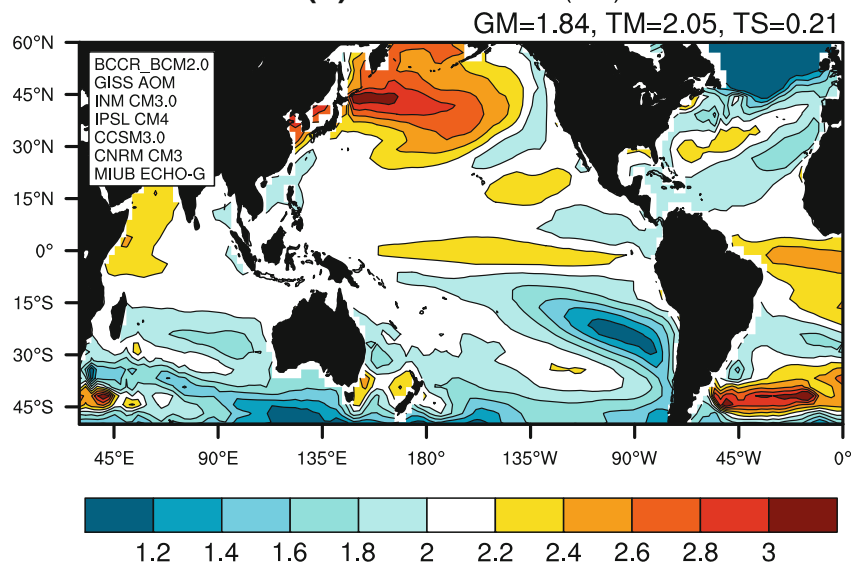

(d) Cluster3 SST (C3)

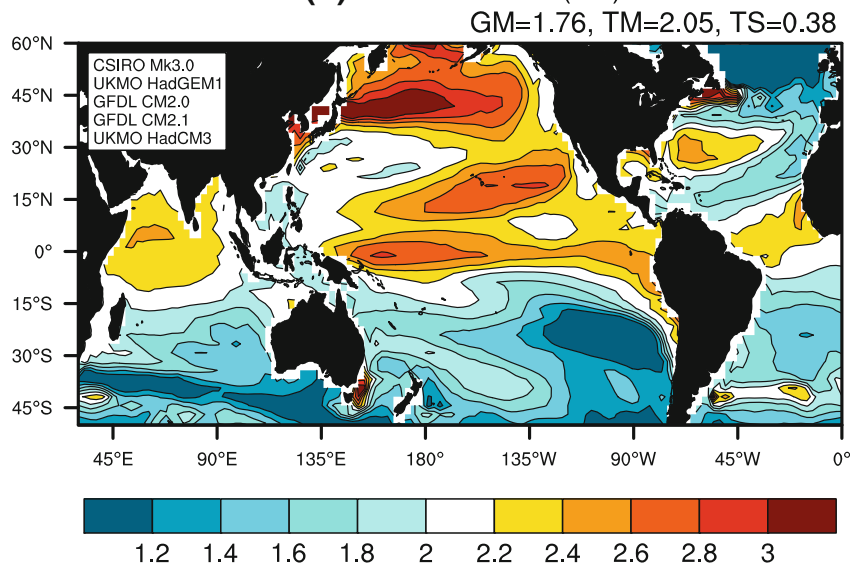

$(\mathrm{GM})$, tropical $\left(30^{\circ} \mathrm{S}-30^{\circ} \mathrm{N}\right)$ mean SST change (TM), and standard deviation of the tropical SST spatial change (TS), respectively. The models listed in the top left corner of each panel are the CMIP3 models grouped in that cluster. See Murakami et al. (2012a) for the details

mean $\left(30^{\circ} \mathrm{S}-30^{\circ} \mathrm{N}\right)$ future change in SST, to investigate the dependency of its variation on future changes in global TC activity (Murakami et al. 2012a). Since all three clustered SSTs show similar spatial patterns in the NIO, NIO SST anomaly should be suitable for the cluster procedure to investigate uncertainty in TC activity in the NIO; however, additional computational resources (beyond those currently available) are required to conduct simulations using the new settings. As a preliminary result, this study shows the results obtained with clustered SST based on the all-tropical domain. We confirm that 14 of the 18 CMIP3 models show a larger increase in SST anomaly in the ARB than in the BOB, as found for all four SST changes in Fig. 1. In all, 15 ensemble simulations are conducted (details of the experiments are listed in Table 1).

Concentrations of green house gases $\left(\mathrm{CO}_{2}, \mathrm{CH}_{4}, \mathrm{~N}_{2} \mathrm{O}\right.$, and CFCs) are set to the global annual-mean values, changing from year to year based on observations and International Panel on Climate Change (IPCC) A1B 
Table 1 Details of multi-physics and multi-SST ensemble simulations

\begin{tabular}{|c|c|c|c|c|c|c|}
\hline Abbreviation & Resolution & $\begin{array}{l}\text { Cumulus } \\
\text { scheme }\end{array}$ & $\begin{array}{l}\text { CMIP3 } \\
\text { mean SST }(\mathrm{C} 0)\end{array}$ & $\begin{array}{l}\text { Cluster } 1 \\
\text { SST (C1) }\end{array}$ & $\begin{array}{l}\text { Cluster 2 } \\
\text { SST (C2) }\end{array}$ & $\begin{array}{l}\text { Cluster } 3 \\
\text { SST (C3) }\end{array}$ \\
\hline MRI-AGCM3.1S_AS & 20 km (S) & AS & $x$ & & & \\
\hline MRI-AGCM3.1H_AS & $60 \mathrm{~km}(\mathrm{H})$ & & $x$ & & & \\
\hline MRI-AGCM3.2S_YS & 20 km (S) & YS & $x$ & & & \\
\hline MRI-AGCM3.2H_YS & $60 \mathrm{~km}(\mathrm{H})$ & & $x$ & $x$ & $x$ & $x$ \\
\hline MRI-AGCM3.2H_KF & $60 \mathrm{~km}(\mathrm{H})$ & $\mathrm{KF}$ & $x$ & $x$ & $x$ & $x$ \\
\hline MRI-AGCM3.2H_AS & 60 km (H) & AS & $x$ & $x$ & $x$ & $x$ \\
\hline
\end{tabular}

$\mathrm{S}(\mathrm{H})$ represents $20(60) \mathrm{km}$ mesh. AS, YS, and KF indicates Arakawa-Schubert, Yoshimura, and Kain-Fritsch scheme, respectively

scenario for the present-day simulations and future projections, respectively. Three-dimensional monthly mean distributions of ozone and aerosols are also given as boundary conditions (see Mizuta et al. 2012 for the details). The prescribed aerosols for the present-day simulations using MRI-AGCM3.2 are obtained from the result of present-day simulation using a prototype version of MRIEarth System Model (ESM1, Yukimoto et al. 2011), in which the historical emission flux of anthropogenic $\mathrm{SO}_{2}$, invariant $\mathrm{SO}_{2}$ flux from non-eruptive volcanoes, and the surface emission inventories for carbonaceous aerosols are prescribed. For the future projections using the MRIAGCM3.2, aerosols are obtained from the result of a future projection based on the IPCC A1B scenario using the MRIESM1. The boundary settings for the MRI-AGCM3.1 are almost identical to those for the MRI-AGCM3.2, except that the zonally mean ozone is used instead of the threedimensional ozone, and aerosols are obtained from a previous version of the MRI aerosol chemical transport model (Tanaka et al. 2003).

\subsection{Observational dataset}

The TC climatology for the control simulations is validated using the global TC dataset compiled on the Unisys Corporation website (Unisys 2012). This dataset consists of best-track TC data provided by the Joint Typhoon Warning Center (JTWC) for TCs in the NIO, and contains historical TC information, such as the location, intensity (maximum 1-min surface wind speed), and central sea level pressure (SLP) of TCs at 6-h intervals from 1945 to 2012. This study considers only TCs of tropical storm intensity or stronger (i.e., TCs that possess 1-min sustained surface wind speeds of $35 \mathrm{kt}$ or greater) between 1979 and 2003.

The Japanese 25-year Re-Analysis (JRA-25) dataset (Onogi et al. 2007) was used for a comparison with the simulated large-scale flows (Sect. 5). The JRA-25 reanalysis system was constructed based on the former global operational forecast and assimilation system at the Japan
Meteorological Agency (JMA). The data available period is from 1979 to 2004; however, this study uses the data between 1979 and 2003 .

\subsection{Detection algorithm for tropical cyclones}

Tropical cyclones are detected in the model by evaluating 6-hourly model outputs using uniform criteria based on those described by Murakami et al. (2012a, b). In short, the model considers low-level vorticity, maximum surface wind speed, radius of maximum wind speed, warm core temperature anomaly, and duration. Some criteria are optimized further in this study for a given model configuration to ensure that the present-day (1979-2003) basintotal mean annual TC number matches that observed (4.56 per year for the period 1979-2003 according to the Unisys dataset).

Tropical cyclone positions are counted for each $2.5^{\circ} \times 2.5^{\circ}$ grid box within the NIO domain at 6-hourly intervals. The TC frequency (TCF) is defined as the total count for each grid box. The location of TC genesis is defined as the position at which the TC is first detected, and the TC genesis frequency (TGF) is defined similarly to TCF. Both TCF and TGF are smoothed using a weighted 9-point average, for which the weights depend on distance from the centre of the grid box. Two sub-ocean basins are also considered in this analysis: ARB and BOB. $77^{\circ} \mathrm{E}$ is set to the boundary between the basins (see Fig. 2 for the regional boundary).

\section{Evaluation of the present-day simulations}

\subsection{TC frequency}

Figure 2 shows annual mean TCF for the present-day simulations using various models. The observations (Fig. 2a) show two spatial peaks (ARB and BOB in the NIO) and spatial contrast in TCF, with larger values in the 
(a) Observations (TCF)

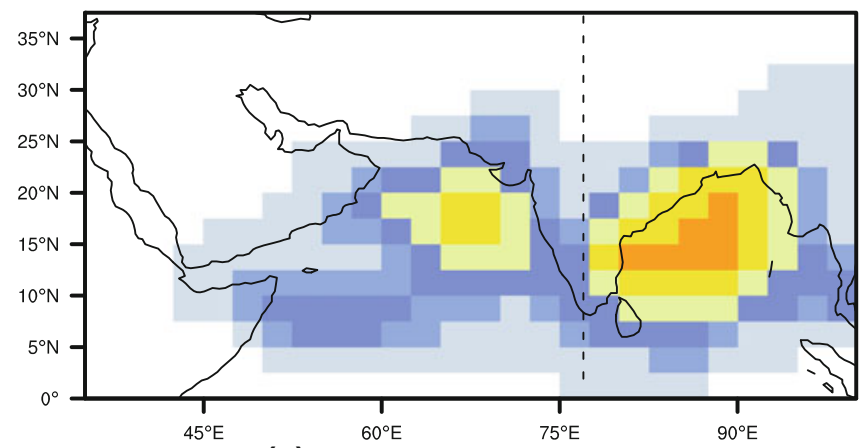

(c) MRI-AGCM3.1H_AS (TCF)

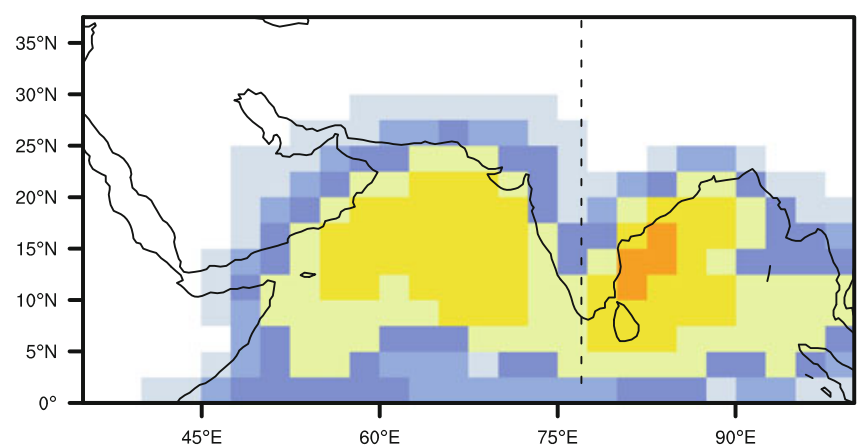

(e) MRI-AGCM3.2H_YS (TCF)

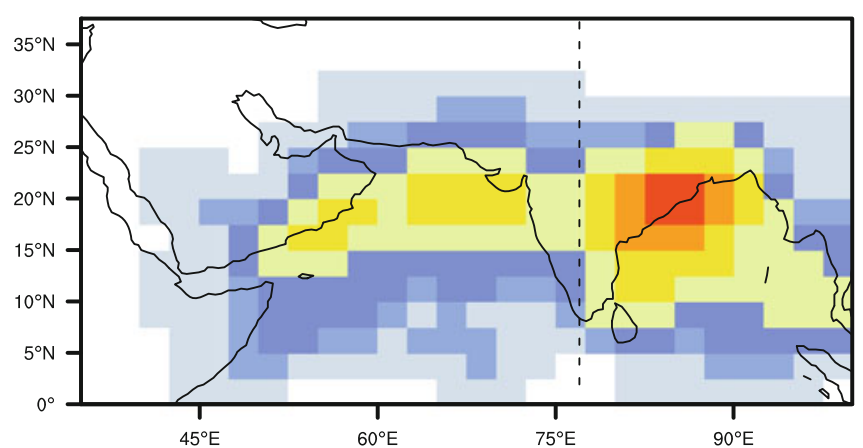

(g) MRI-AGCM3.2H_AS (TCF)

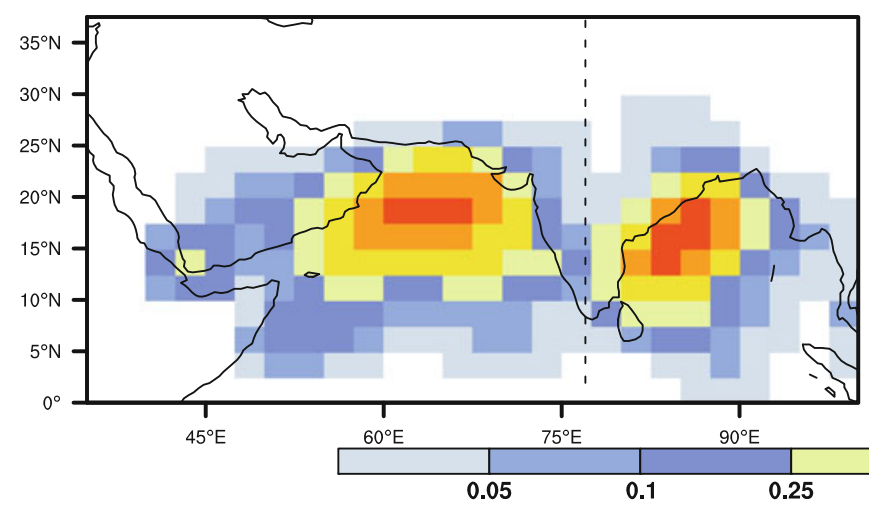

Fig. 2 Annual mean tropical cyclone frequency (TCF) from 1979 to 2003 according to a observations, $\mathbf{b}$ the control simulation using MRIAGCM3.1S_AS, c MRI-AGCM3.1H_AS, d MRI-AGCM3.2S_YS, (b) MRI-AGCM3.1S_AS (TCF)

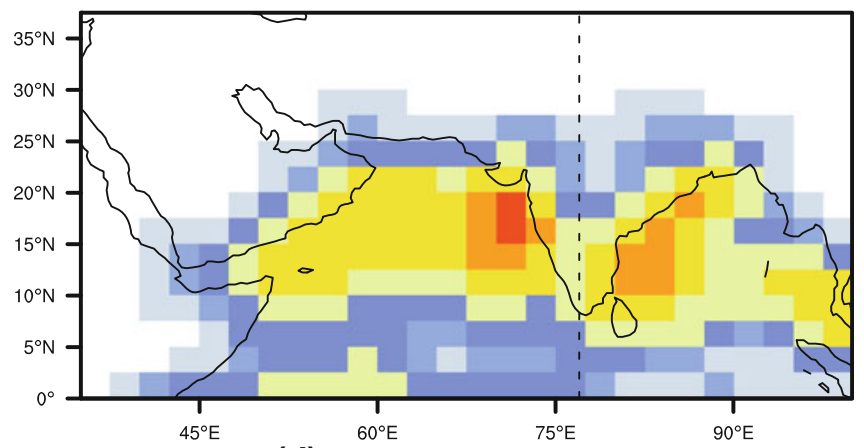

(d) MRI-AGCM3.2S_YS (TCF)

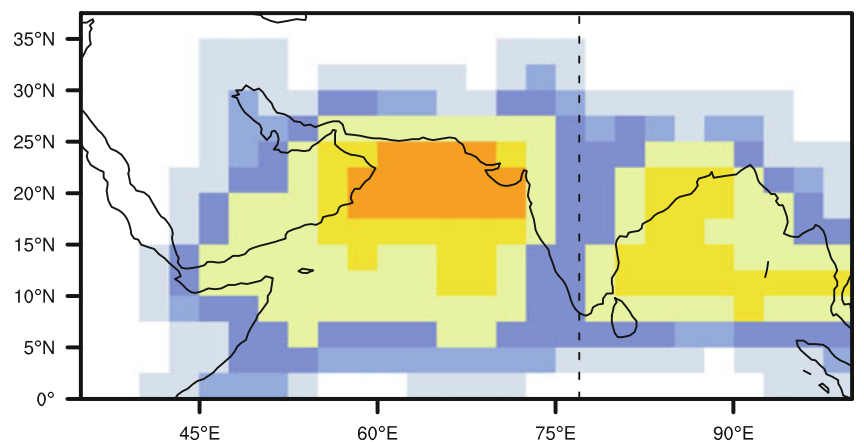

(f) MRI-AGCM3.2H_KF (TCF)

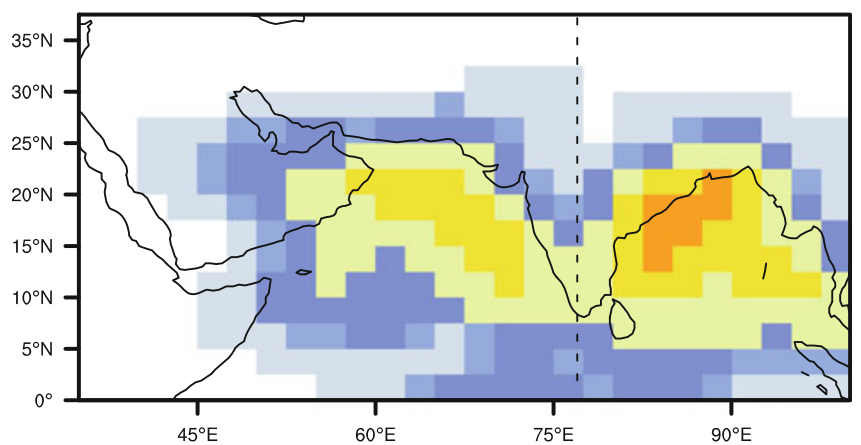

(h) Ensemble Mean (TCF)

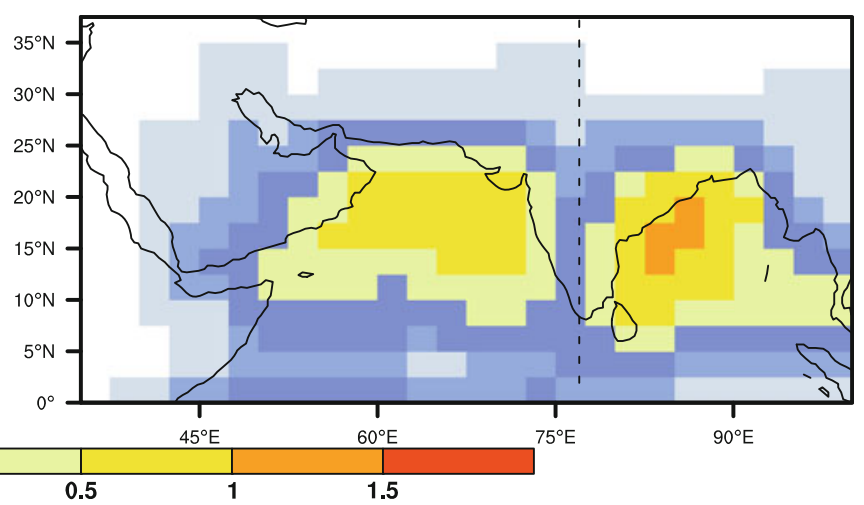

e MRI-AGCM3.2H_YS, f MRI-AGCM3.2H_KF, and g MRIAGCM3.2H_YS. h Ensemble mean of $\mathbf{b}-\mathbf{g}$. Unit is number per year 
(a) North Indian Ocean

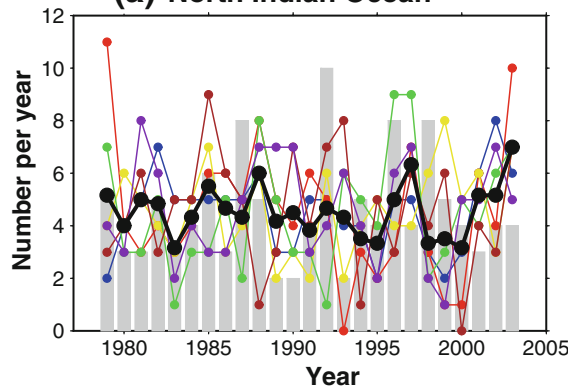

(d) North Indian Ocean

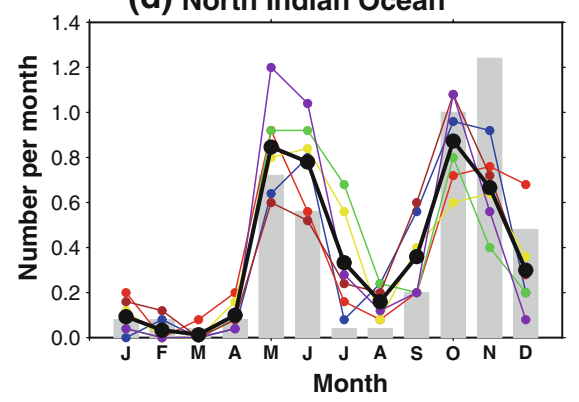

$\longrightarrow$ MRI-AGCM3.1S_AS $\longrightarrow$ MRI-AGCM3.2H_KF

$\bullet$ MRI-AGCM3.1H_AS $\bullet$ MRI-AGCM3.2H AS

$\multimap$ MRI-AGCM3.2S_YS $\multimap$ Ensemble mean

$\longrightarrow$ MRI-AGCM3.2H YS

Fig. 3 Interannual variation in TC genesis number during all seasons from 1979 to 2003 according to observations (grey bars) and simulation results (colour lines) for a NIO, b BOB, and $\mathbf{c}$ ARB. Black

BOB than in the ARB. The simulated TCFs also show the spatial peaks; however, some models show larger TCF in the ARB than in the BOB, which differs from observations. The ensemble mean in Fig. $2 \mathrm{~h}$ shows a reasonable TCF distribution in the NIO and an overestimate in the ARB.

\subsection{Temporal variations in TC genesis number}

Figure 3 shows simulated interannual and seasonal variations in TC genesis number compared with observations. Although the simulated standard deviation of interannual variations appears to be reasonable compared with observations, correlation coefficients between simulation results and observations (Table 2) indicate that the models have no skill in simulating the observed year-to-year variations, except for MRI-AGCM3.2S_YS (see also Murakami et al. 2012b). Previous studies, using state-of-the-art models, also reported difficulties in simulating interannual variations in TC genesis number in the NIO (e.g., Zhao et al. 2009). Simulated seasonal variations in TC genesis number appear to capture observed variations to some degree (Fig. 3d-f), showing peaks during May-June (pre-monsoon season) and October-November (post-monsoon season); however, models tend to generate more TCs during July-September (peak-monsoon season) compared with lines indicate the ensemble mean of the simulations. $\mathbf{d}-\mathbf{f}$ As in $\mathbf{a}-\mathbf{c}$, but for the seasonal mean variation in TC genesis number

Table 2 Correlation coefficients of interannual variations in TC genesis number between simulation results and observations for (a) NIO, (b), BOB, and (c) ARB

\begin{tabular}{lccc}
\hline & $\begin{array}{l}\text { (a) North } \\
\text { Indian Ocean }\end{array}$ & $\begin{array}{l}\text { (b) Bay } \\
\text { of Bengal }\end{array}$ & \multicolumn{2}{l}{$\begin{array}{l}\text { (c) Arabian } \\
\text { Sea }\end{array}$} \\
\hline MRI-AGCM3.1S_AS & 0.06 & 0.36 & -0.09 \\
MRI-AGCM3.1H_AS & 0.07 & -0.16 & 0.20 \\
MRI-AGCM3.2S_YS & 0.38 & 0.19 & 0.42 \\
MRI-AGCM3.2H_YS & -0.13 & -0.24 & 0.04 \\
MRI-AGCM3.2H_KF & -0.03 & -0.04 & 0.19 \\
MRI-AGCM3.2H_AS & -0.23 & 0.02 & -0.19 \\
Ensemble mean & 0.02 & 0.00 & 0.16 \\
\hline
\end{tabular}

observations (see Sect. 5 for the details). Simulated seasonal cycles in TC number in the BOB (Fig. 3e) are reasonable compared with observations except for MRIAGCM3.2H_YS, but show peaks that are slightly earlier in the post-monsoon season than in the observations. The simulated TC number in the ARB (Fig. 3f) shows a peak in the pre-monsoon season rather than in the post-monsoon season, which differs from observations. The correlation coefficients of seasonal variations in TC genesis number between simulations and observations range from 0.6 and 
Table 3 As in Table 2, but for seasonal variations in TC genesis number

\begin{tabular}{llll}
\hline & $\begin{array}{l}\text { (a) North } \\
\text { Indian Ocean }\end{array}$ & $\begin{array}{l}\text { (b) Bay } \\
\text { of Bengal }\end{array}$ & $\begin{array}{l}\text { (c) Arabian } \\
\text { Sea }\end{array}$ \\
\hline MRI-AGCM3.1S_AS & 0.88 & 0.84 & 0.80 \\
MRI-AGCM3.1H_AS & 0.89 & 0.92 & 0.64 \\
MRI-AGCM3.2S_YS & 0.71 & 0.79 & 0.71 \\
MRI-AGCM3.2H_YS & 0.57 & 0.58 & 0.62 \\
MRI-AGCM3.2H_KF & 0.84 & 0.84 & 0.74 \\
MRI-AGCM3.2H_AS & 0.73 & 0.83 & 0.69 \\
Ensemble mean & 0.02 & 0.88 & 0.78 \\
\hline
\end{tabular}

0.9 (Table 3), indicating that the models can simulate seasonal variations better than interannual variations.

The reason why the models are better at simulating seasonal variations than interannual variations is not yet clear. The bimodal seasonal cycle of TC frequency in the NIO is strongly controlled by the seasonal evolution of the Asian monsoon through the intense local vertical wind shear (Gray 1968). Mizuta et al. (2012) reported that the models give a reasonable simulation of the seasonal evolution in the NIO (e.g., the sudden onset and gradual withdrawal of the monsoon). In contrast, the factors responsible for the interannual variations in TC frequency appear to be more complex in the NIO. One of the major drivers of the interannual variability is El Niño and Southern Oscillation (ENSO; Singh et al. 2000; Camargo et al. 2007). However, Singh et al. (2000) reported that correlation coefficients between the Southern Oscillation Index (SOI) and annual TC number over the BOB are only +0.3 and +0.2 during May and November, respectively. Moreover, they reported that the correlation coefficients for the ARB are not statistically significant, implying that ENSO has only limited impact on the TC number over the ARB. Evan and Camargo (2011) found a 5-6-year periodicity in the Genesis Potential Index (GPI) from 1985 to 2008 in the ARB. Although they suggest that the periodicity is physical, it is difficult to identify the mechanism responsible.

\section{Projected future changes}

\subsection{TC genesis number}

Figure 4 shows projected fractional future changes in TC genesis number for each ensemble experiment. The projected future changes in TC number are not statistically significant in the NIO and sub-basins, except for the ensemble mean using the KF scheme in the $\mathrm{NIO}$ and $\mathrm{BOB}$ and ensemble mean using the $\mathrm{C} 2 \mathrm{SST}$ in the $\mathrm{BOB}$, although most experiments tend to show reductions in the $\mathrm{BOB}$ and increases in the ARB. The standard deviations of the projected fractional future changes are $10-17 \%$, indicating that the future changes in TC number are not robust among these experiments. Cluster 2 SST experiments show a slightly larger reduction in the BOB (Fig. 4b), while Cluster 3 SST experiments show a smaller reduction in the ARB (Fig. 4c). Inter-cumulus variation seems to be larger than inter-SST variation in the BOB (Fig. 4b); this difference is not apparent in the ARB.

\subsection{Tropical cyclone frequency}

Figure 5 shows ensemble mean projected future changes in the spatial distributions of TCF and TGF. Locations where these changes are robust and statistically significant are marked with plus symbols in the figure. TCF is projected to increase significantly and robustly in the northern ARB (region $A$ in Fig. 5) by about $46 \%$ and decrease in the west of BOB (region $B$ in Fig. 5) by about $32 \%$. This spatial contrast is also seen in future changes in TC number (see Fig. 4). A similar east-west spatial contrast in TCF changes was reported by Emanuel (2008), who employed a statistical-dynamical downscaling model. TCF and TGF (a) North Indian Ocean

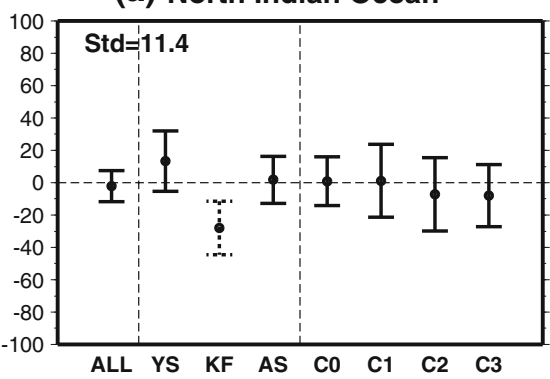

(b) Bay of Bengal

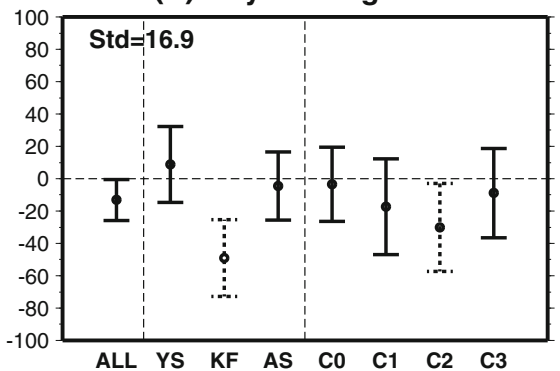

(c) Arabian Sea

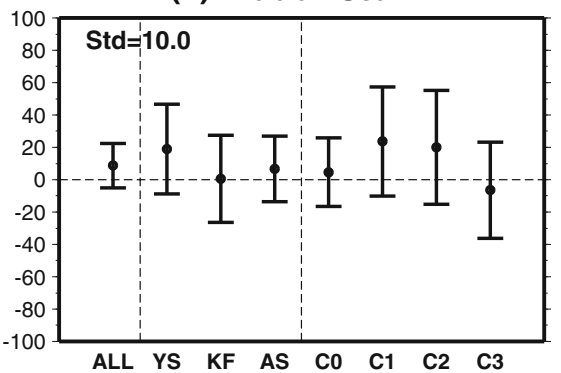

Fig. 4 Fractional future changes $(\%)$ in TC genesis number for each basin according to each ensemble experiment. The error bars indicate $99 \%$ confidence intervals. Dashed error bars indicate projected future changes that are statistically significant at the $99 \%$ level (twosided Student's $t$ test). ALL indicates the all-ensemble mean. YS, KF, and KF, indicate the ensemble mean of projections with the YS, KF, and $\mathrm{AS}$ cumulus schemes, respectively. $\mathrm{C} 0, \mathrm{C} 1, \mathrm{C} 2$, and $\mathrm{C} 3$ indicate the ensemble mean of projections with the CMIP3 mean, Cluster 1, Cluster 2, and Cluster 3 SSTs, respectively. Std standard deviation among the ensemble means 
Fig. 5 a Ensemble mean future changes in tropical cyclone frequency (TCF) [number/ 25 years]. The plus symbols indicate that the differences are statistically significant at the $99 \%$ confidence level or above (two-sided Student's $t$ test) and that more than $80 \%$ of the ensemble members project mean changes of the same sign. b As in a, but for tropical cyclone genesis frequency (TGF). The regions labelled in the figure $(A, B)$ are discussed in the text (a) Ensemble Mean of Future Changes in TCF

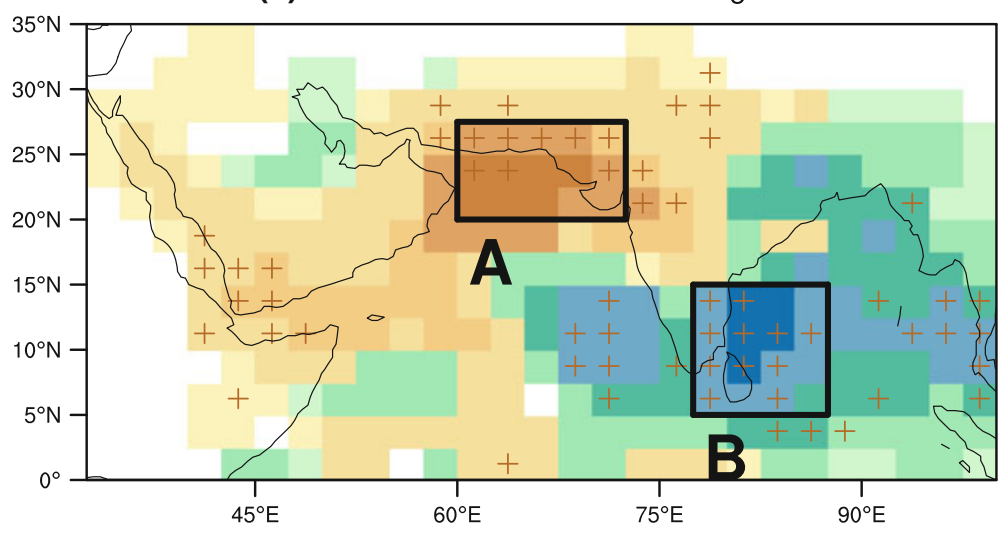

number/25-year

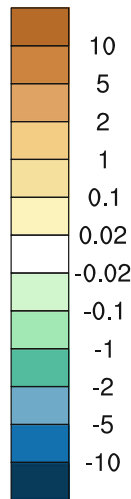

(b) Ensemble Mean of Future Changes in TGF

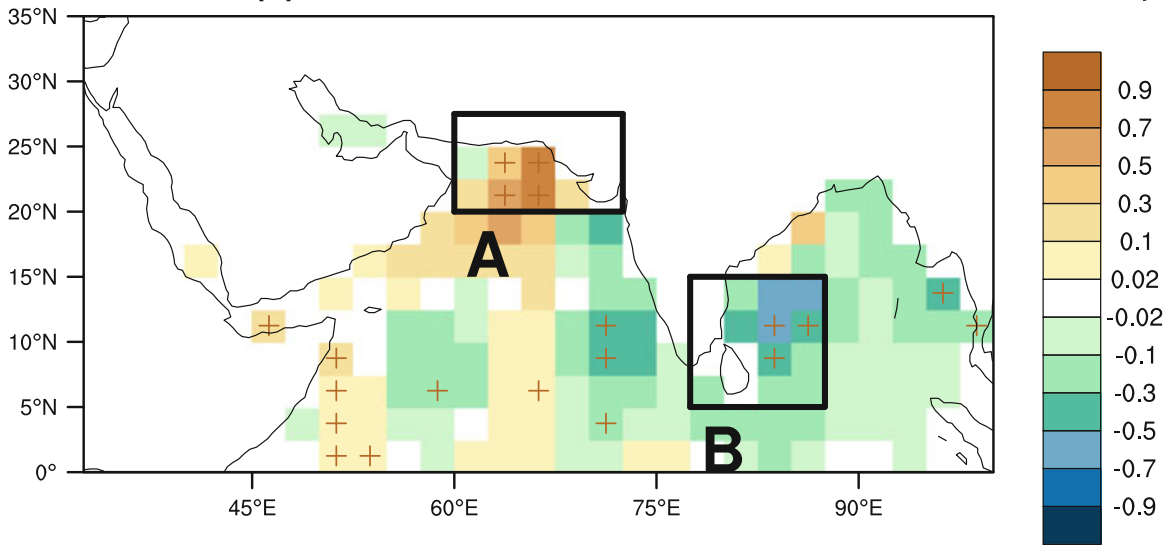

show similar spatial patterns, indicating future changes in local TGF are of primary importance to those in TCF. The dominance of TGF is not surprising considering that the average lifetime of TCs in the NIO is relatively short compared with the other ocean basins. TCF is also projected to increase in the Gulf of Aden, although the control simulations overestimate TCF in this region (Fig. 2). Note that there are grid cells showing significant and robust TCF increases over the land surface in the ARB, indicating an increasing potential for future catastrophic damage in this region.

Figure 6 shows the ensemble mean of future changes in TCF averaged for experiments with either the same SST or the same cumulus convection scheme. Generally, robust geographical distributions of TCF changes are seen regardless of SST (Fig. 6a-d) and the choice of cumulus convection scheme (Fig. 6e-g), except that the ensemble mean of experiments with the KF scheme shows a future decrease in TCF in the ARB (but this is not robust among the experiments with different SSTs).

To assess the relative importance of TGF and TC tracks in terms of future changes in TCF, we analysed TCF changes using a TCF analysis method as follows. TCF in a region $A$ can be written as the follows:
$\operatorname{TCF}(A)=\iint g\left(A_{0}\right) t\left(A, A_{0}\right) d A_{0}$,

where $\mathrm{TCF}(A)$ is the TCF in region $A, g\left(A_{0}\right)$ is TGF in grid cell $A_{0}$, and $t\left(A, A_{0}\right)$ is the probability that a TC generated in region $A_{0}$ travels to region $A$. Future change in TCF is computed using a variational method as follows.

$\delta \mathrm{TCF}=\delta G \times T+G \times \delta T+\delta G \times \delta T$,

where $\delta$ is future change (relative to the present day). Future change in TCF is decomposed into three factors: future change due to (a) TC genesis distribution (first term), (b) TC tracks (second term), and (c) the complex nonlinear effect (third term).

Figure 7 shows the contribution of each term to the total TCF change for the regions $A$ and $B$ shown in Fig. 5. The relative contributions for each term to the total TCF change in the region $A$ are $+62,+8$, and $+30 \%$ for the TC genesis, track, and nonlinear terms, respectively, while those in the region $B$ are $+76,+45$, and $-21 \%$, respectively. The TC genesis factor is primarily responsible for the TCF changes for both the regions. Although the TC track factor is of secondary importance for the TCF changes, the increase in TCF in the ARB is due in part to a TC track 
(a) Co SST Ensemble (TCF)

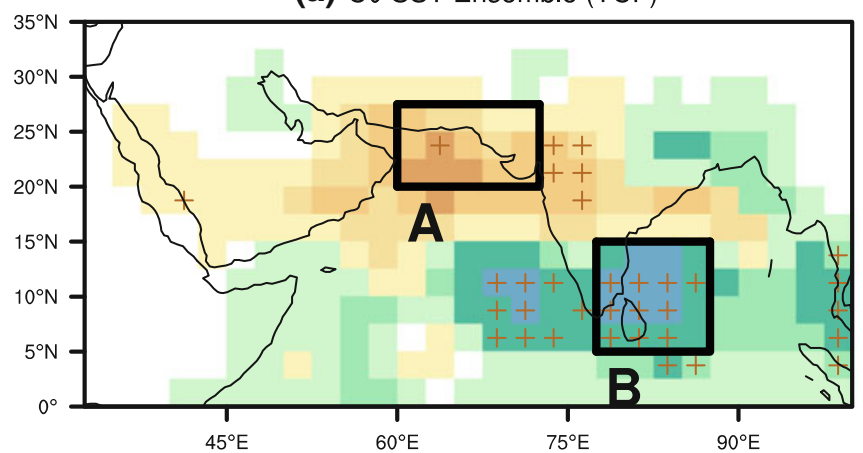

(c) C2 SST Ensemble (TCF)

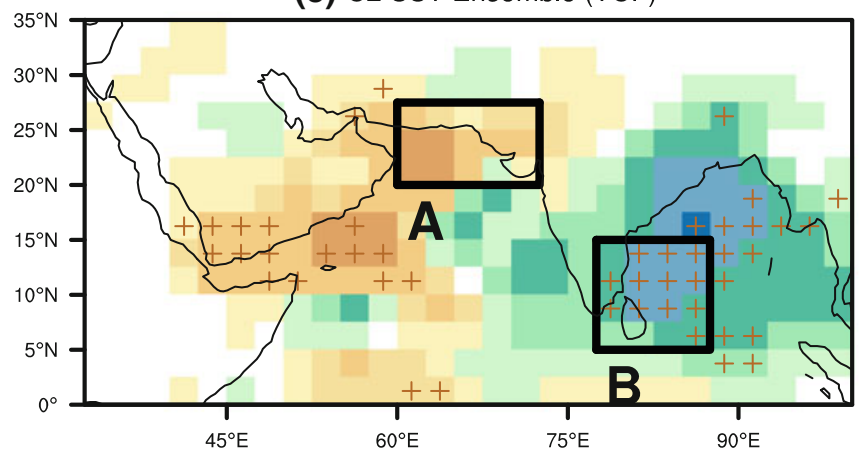

(e) YS Ensemble (TCF)

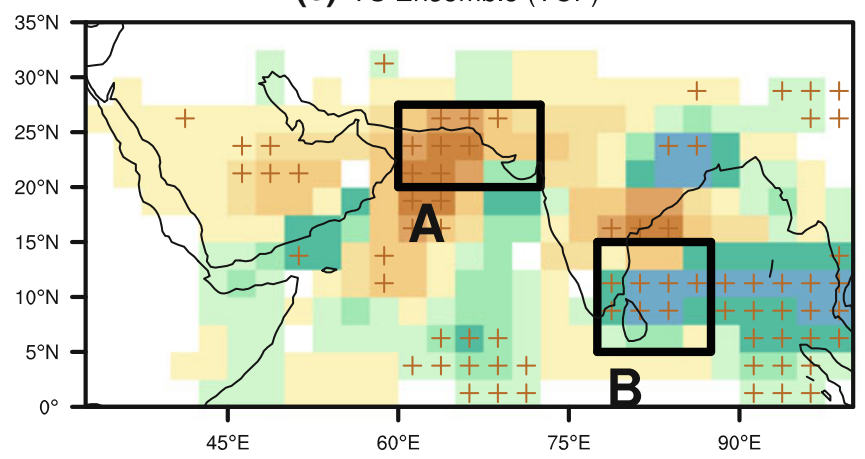

(g) AS Ensemble (TCF)

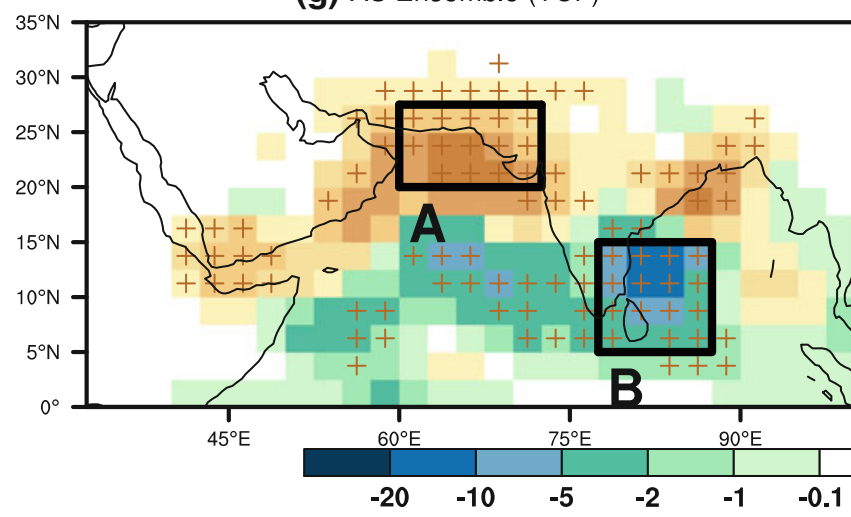

Fig. 6 As in Fig. 5a, but for ensemble mean of a CMIP3 SST experiments, b Cluster 1 SST experiments, c Cluster 2 SST experiments, d Cluster 3 SST experiments, and experiments using e the Yoshimura convection scheme (YS), f the Kain-Fritsch (KF) (b) C1 SST Ensemble (TCF)

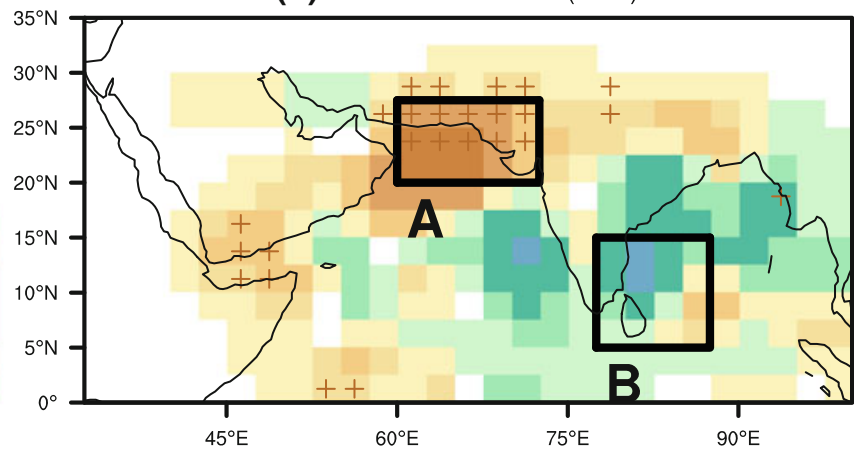

(d) C3 SST Ensemble (TCF)

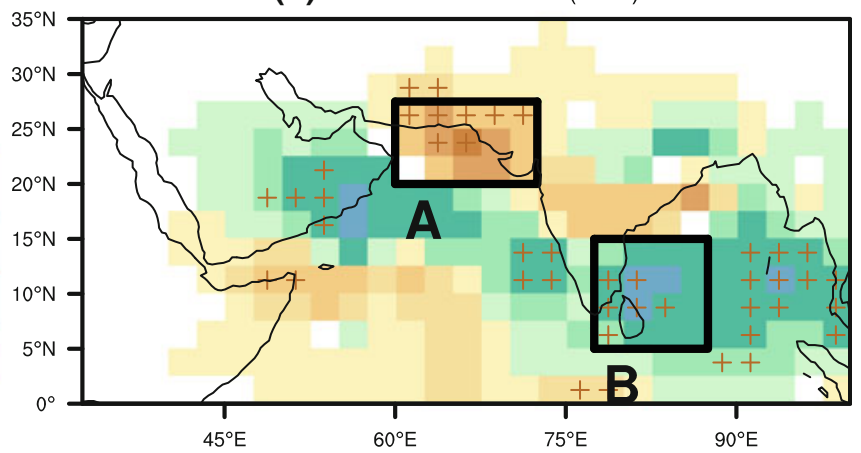

(f) KF Ensemble (TCF)

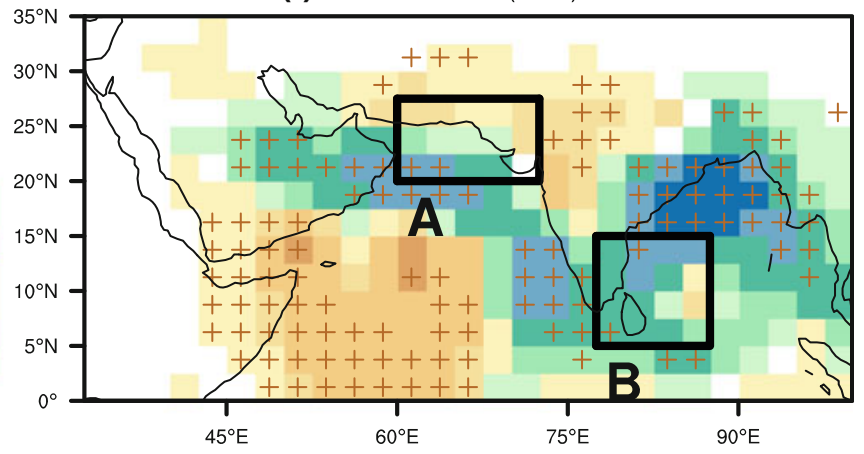

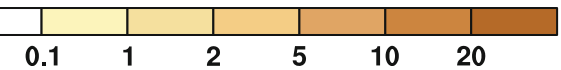

convection scheme, and $\mathbf{g}$ the Arakawa-Schubert (AS) convection scheme. The regions labelled in the figure $(A$ and $B)$ are discussed in the text 
(a) $\delta \mathrm{G} \times \mathrm{T}$

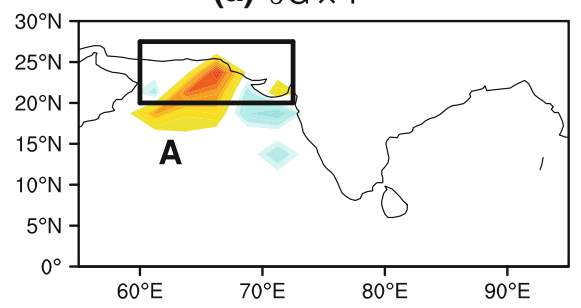

(d) $\delta \mathrm{G} \times \mathrm{T}$

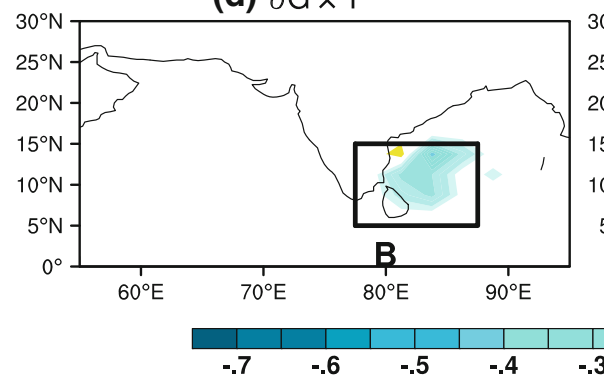

Fig. 7 Ensemble mean contribution of each term to changes in TC frequency (TCF) during all seasons. Factors that influence TCF in the Arabian Sea are TC genesis (a), TC tracks (b), and nonlinear effect

shift from the BOB (Fig. 7b), which indicates a westward shift of TC tracks.

\section{Discussion}

Given that TGF changes account for the bulk of TCF changes (see above), we focus on the physical mechanisms that underlie the TGF changes. Figure 8 shows the simulated and projected monthly mean TC genesis number for each basin, revealing a marked seasonal variation in the projected future changes in TC number. Although projected future changes in monthly TC number are not statistically significant due to large year-to-year variations, the projected TC number over the pre-monsoon season of April-May decreases in the future for all basins, while that over the peak-monsoon season of June-August increases. Note that the models have biases of generating more TCs during the peak-monsoon season compared with observations. Previous studies suggest that observed TCs forming during the peak-monsoon season are shear limited (Gray 1968; Evan et al. 2011), so that these model biases could be inherited by projections of future change during the peakmonsoon season. Projected TC number over the postmonsoon season of October-December shows a decrease in the BOB and no change in the ARB. Figure 9 shows projected future changes in TGF for each season. In the premonsoon season, TGF is projected to decrease significantly and consistently in both the ARB and BOB (Fig. 9a). In contrast, TGF is projected to increase in both the ARB and BOB in the peak-monsoon season (Fig. 9b). In the post- (c) $\delta G \times \delta T$

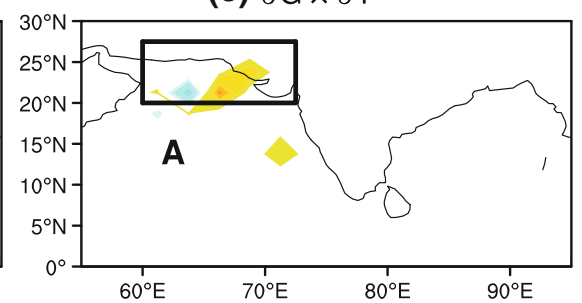

(f) $\delta G \times \delta T$

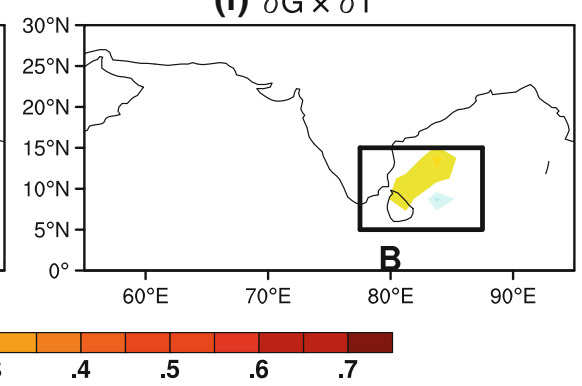

(c). d-f As in a-c, but for TCF changes in the Bay of Bengal. The regions labelled in the figure $(A$ and $B$ ) are discussed in the text

monsoon season, TGF is projected to increase in the ARB and to decrease in the BOB (Fig. 9c), showing a similar spatial pattern to that over the whole year (Fig. 5b). It appears that the spatial pattern in TGF change in the postmonsoon season is responsible for that over the whole year shown in Fig. 5b, because pre- and peak-season changes appear to cancel each other out.

Several factors may be associated with TGF change. For example, previous studies have reported relationships between large-scale dynamical and thermodynamic parameters, and variations in TC genesis (Gray 1968; Emanuel and Nolan 2004). Here we examine the extent to which projected future changes in TGF can be explained by the following large-scale parameters (as also investigated by Murakami et al. 2012a): relative vorticity at $850 \mathrm{hPa}$ $\left(\eta_{850}\right)$; relative humidity at $700 \mathrm{hPa}(\mathrm{RH})$; maximum potential intensity ( $V_{\text {pot }}$; Bister and Emanuel 1998); vertical wind shear between 200 and $850 \mathrm{hPa}\left(V_{\mathrm{s}}\right)$, defined as the magnitude of the vector difference between winds at 200 and $850 \mathrm{hPa}$; vertical pressure-velocity at $500 \mathrm{hPa}\left(\omega_{500}\right)$; saturation deficit in the lower troposphere $(\chi)$; atmospheric static stability $\left(\Gamma_{\mathrm{d}}\right)$; synoptic scale disturbances $(D$; Lau and Lau 1990), defined as the variance of 2-8-day bandpass filtered $850 \mathrm{hPa}$ vorticity; vertical shear of zonal wind $\left(V_{\mathrm{zs}}\right)$, defined as difference in zonal component of winds between 200 and $850 \mathrm{hPa}$ (i.e., $V_{\mathrm{zs}} \equiv u_{200}-u_{850}$ ); and SST anomaly $\left(S_{\mathrm{a}}\right)$, defined by subtracting the tropical mean $\left(30^{\circ} \mathrm{S}-30^{\circ} \mathrm{N}\right)$ change in SST from the local change.

The pattern correlation between the plotted quantity and projected TGF changes is shown in the top right of each panel in Fig. 10. Although the correlation coefficients are 

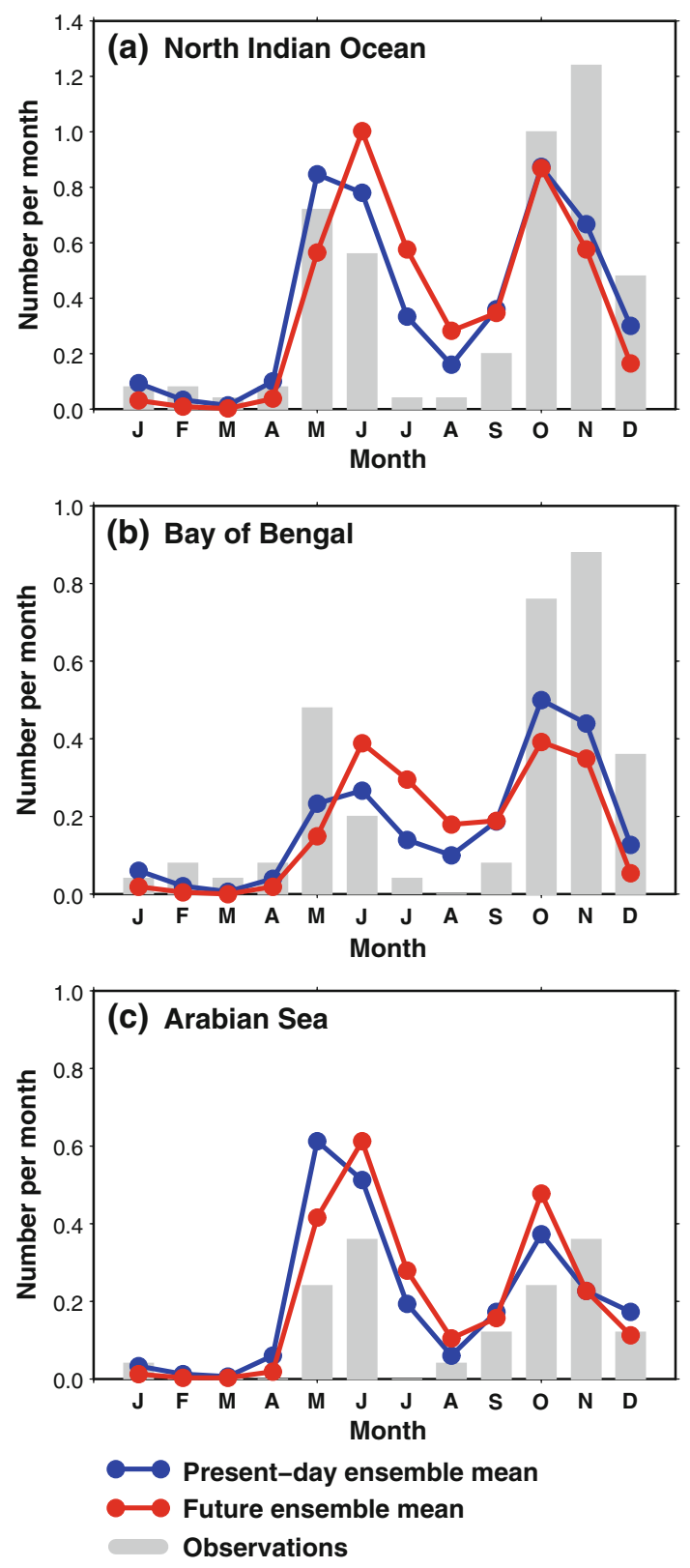

Fig. 8 Monthly mean TC genesis number according to observations (1979-2003, grey bars), ensemble mean of present-day simulations (1979-2003, blue lines), and future projections (2075-2099, red lines) for $\mathbf{a}$ the NIO, $\mathbf{b}$ the BOB, and $\mathbf{c}$ the ARB

small for all parameters, the dynamical parameters (e.g., $\eta_{850}, V_{\mathrm{s}}, V_{\mathrm{zs}}$, and $D$ ) show higher positive spatial correlations with the future change in TGF than do the thermodynamic parameters. The highest pattern-correlation field for the TGF pattern is with $\eta_{850}(r=0.54)$. Vertical wind shear is also positively correlated with the TGF pattern. Figure 11 shows the projected April-May mean of largescale circulation at 850 and $200 \mathrm{hPa}$. During the premonsoon season, the low-level southwesterly Somali jet is weak in the western NIO in both present-day simulations and future projections, and the low-level equatorial NIO (a) $\delta$ TGF $\left[\mathrm{AM}, 10^{-2}\right.$ number $\left.\mathrm{yr}^{-1}\right]$

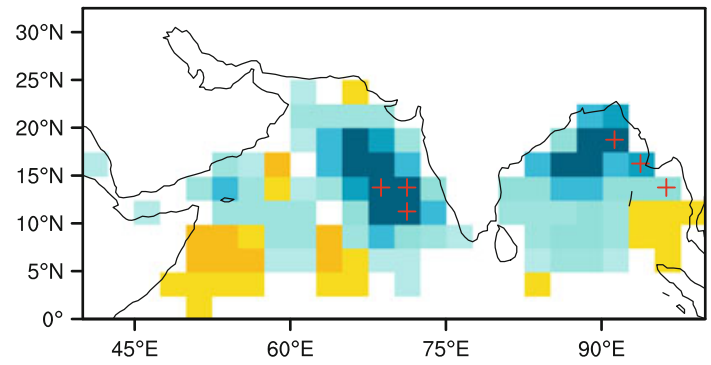

(b) $\delta$ TGF [JJA, $10^{-2}$ number $\left.\mathrm{yr}^{-1}\right]$

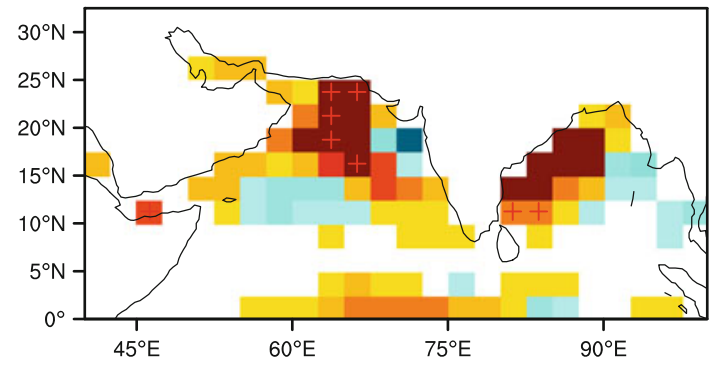

(c) $\delta$ TGF [OND, $10^{-2}$ number $\left.\mathrm{yr}^{-1}\right]$

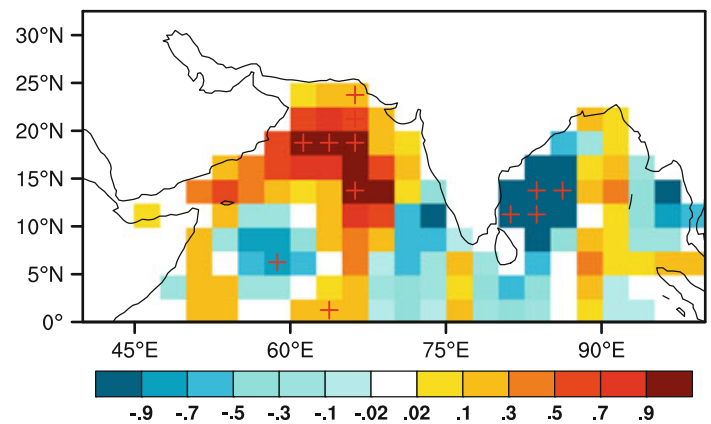

Fig. 9 As in Fig. 5b, but for the seasonal mean of a April-May (AM), b June-August (JJA), and October-December (OND). Unit is $10^{-2}$ number per year

exhibits cyclonic circulation (Fig. 11a, b). Projected future changes in the low-level circulation show an anticyclonic anomaly (Fig. 11c), indicating weakening of low-level large-scale circulation. The significant reductions in the projected TGF occurred in the anticyclonic anomaly regions (Fig. 11c), indicating that the weakening of lowlevel circulation is one of the factors responsible for the reduction in the TGF. The large-scale upper-level circulation exhibits strong westerly and anticyclonic flows in the pre-monsoon season (Fig. 11d, e). Projected future changes show an increase in the westerly flows north of $15^{\circ} \mathrm{N}$, resulting in strong westerly vertical wind shear (Fig. 11i). Because regions of marked reduction in TGF are located north of $10^{\circ} \mathrm{N}$ (Fig. 9a), the increase in the vertical wind shear may be of secondary importance for the reduction in the TGF in the future.

In the present climate, it is known that vertical wind shear is one of the important large-scale parameters that 
(a) $\delta S_{a}[K]$

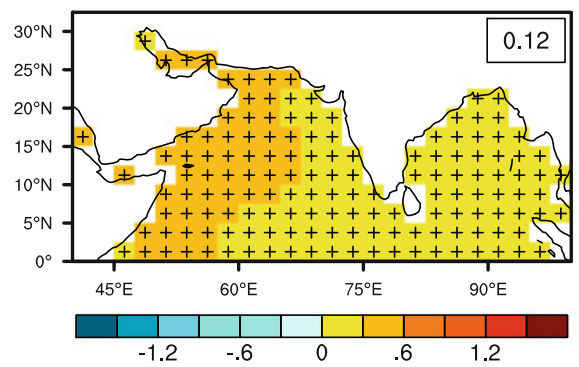

(d) $-\delta \chi\left[10^{2} \mathrm{~Pa}\right]$

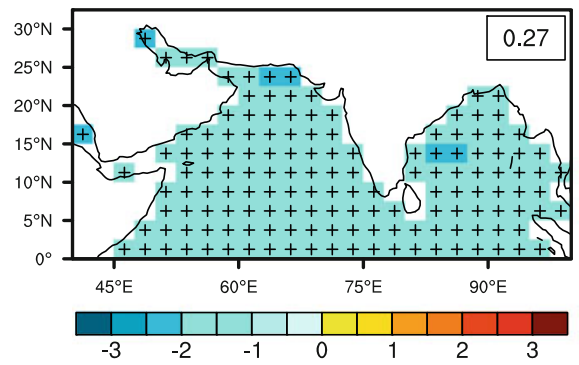

(f) $\delta \eta_{850}\left[10^{-6} \mathrm{~s}^{-1}\right]$

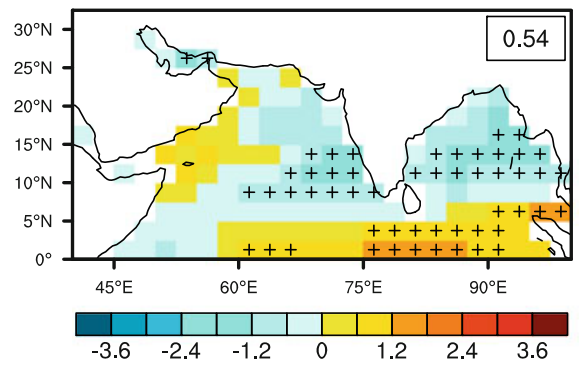

(i) $-\delta \omega_{500}\left[10^{-2} \mathrm{~Pa} \mathrm{~s}^{-1}\right]$

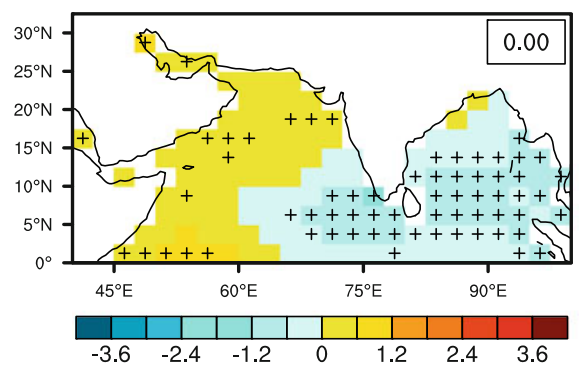

Fig. 10 Future changes in large-scale weighted parameters according to the full ensemble mean: a SST anomaly (K), b relative humidity at $700 \mathrm{hPa}(\%)$, c maximum potential intensity $\left(\mathrm{m} \mathrm{s}^{-1}\right)$, d saturation deficit at $700 \mathrm{hPa}\left(10^{2} \mathrm{~Pa}\right)$, and e static stability $(\mathrm{K})$ for thermodynamic parameters; and $\mathbf{f}$ relative vorticity at $850 \mathrm{hPa}\left(10^{-6} \mathrm{~s}^{-1}\right)$ (positive values indicate cyclonic), $\mathbf{g}$ vertical wind shear $\left(\mathrm{m} \mathrm{s}^{-1}\right)$, h vertical zonal wind shear $\left(\mathrm{m} \mathrm{s}^{-1}\right)$, $\mathbf{i}$ vertical pressure-velocity at (b) $\delta \mathrm{RH}[\%]$

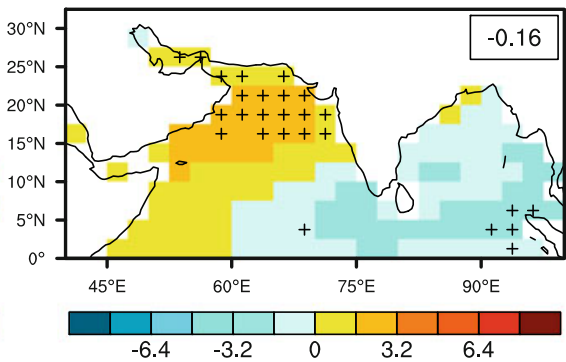

(e) $-\delta \Gamma_{\mathrm{d}}[\mathrm{K}]$

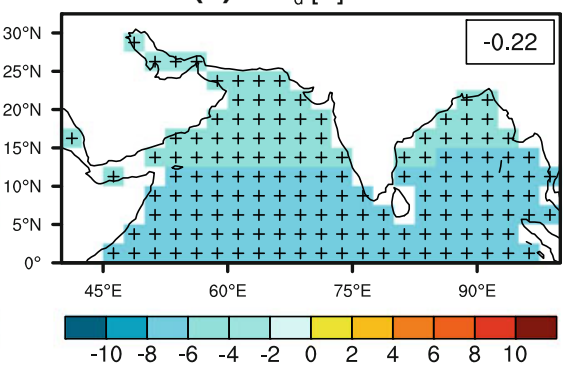

(g) $-\delta \mathrm{V}_{\mathrm{s}}\left[\mathrm{m} \mathrm{s}^{-1}\right]$

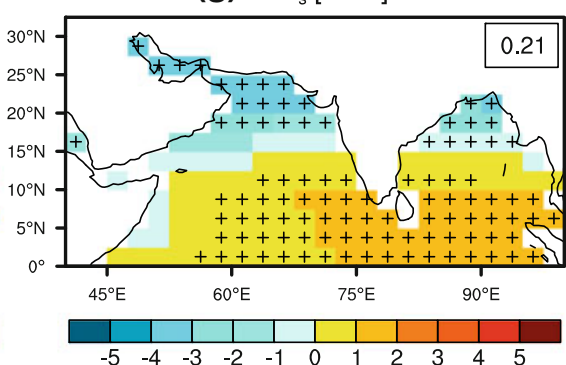

(j) $\delta \mathrm{D}\left[10^{-10} \mathrm{~s}^{-2}\right]$

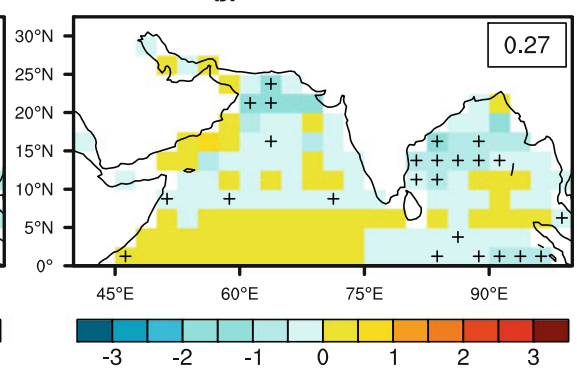

(c) $\delta \mathrm{V}_{\mathrm{pot}}\left[\mathrm{m} \mathrm{s}^{-1}\right]$

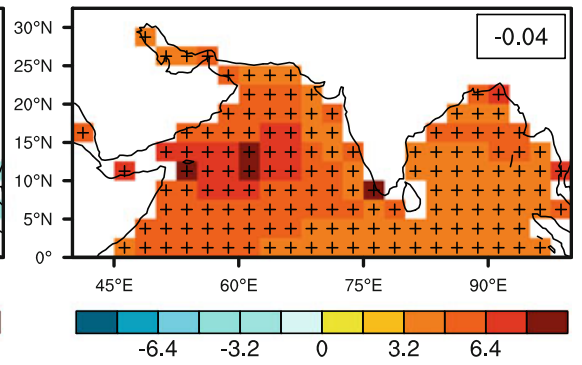

6.4 (h) $-\delta \mathrm{V}_{z \mathrm{~s}}\left[\mathrm{~m} \mathrm{~s}^{-1}\right]$

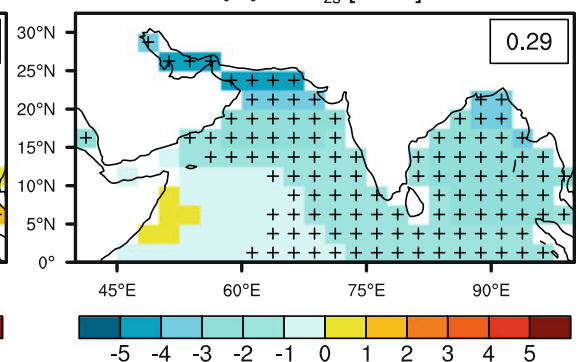

$500 \mathrm{hPa}\left(10^{-2} \mathrm{~Pa} \mathrm{~s}^{-1}\right)$, and $\mathbf{j}$ synoptic-scale disturbances $\left(10^{-10} \mathrm{~s}^{-2}\right)$ for dynamical parameters. The number in the top right of each panel is the spatial correlation coefficient between the plotted quantity and the projected changes in TGF. The plus symbols indicate ensemblemean differences that are consistent among more than 12 of the experiments (i.e., $80 \%$ of all ensemble experiments). The regions labelled in the figure $(A$ and $B)$ are discussed in the text

for the observed vertical shear. Observations indicate that TC genesis occurs frequently at a vertical wind shear of between 5.0 and $12.5 \mathrm{~m} \mathrm{~s}^{-1}$. When the vertical wind shear is greater than $20.0 \mathrm{~m} \mathrm{~s}^{-1}$, TC genesis rarely occurs. About $60 \%(80 \%)$ of TCs are generated at vertical wind shear less than $12.5 \mathrm{~m} \mathrm{~s}^{-1}\left(20 \mathrm{~m} \mathrm{~s}^{-1}\right)$. These features are also 
(a) Wind at $850 \mathrm{hPa}\left[\mathrm{PD}, \mathrm{m} \mathrm{s}^{-1}\right]$

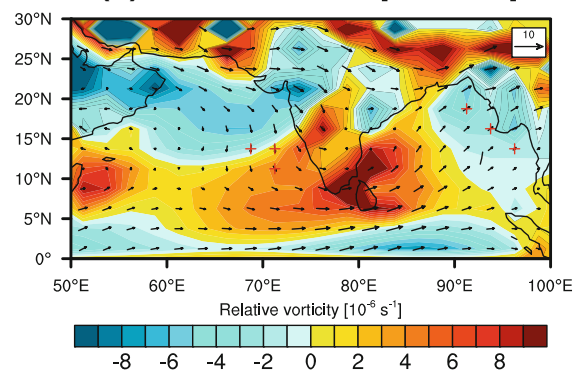

(d) Wind at $200 \mathrm{hPa}\left[\mathrm{PD}, \mathrm{m} \mathrm{s}^{-1}\right]$

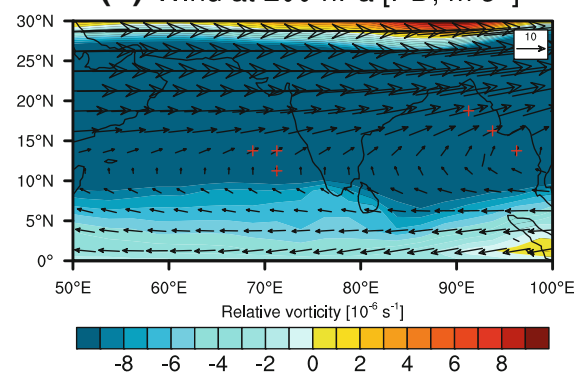

(g) Vert. wind shear [PD, $\left.\mathrm{m} \mathrm{s}^{-1}\right]$

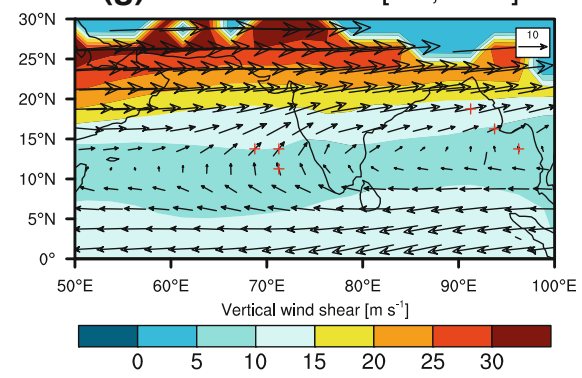

(b) Wind at $850 \mathrm{hPa}$ [GW, $\mathrm{m} \mathrm{s}^{-1}$ ]

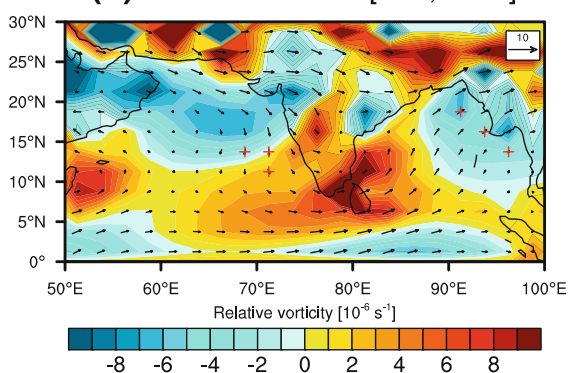

(e) Wind at $200 \mathrm{hPa}$ [GW, $\mathrm{m} \mathrm{s}^{-1}$ ]

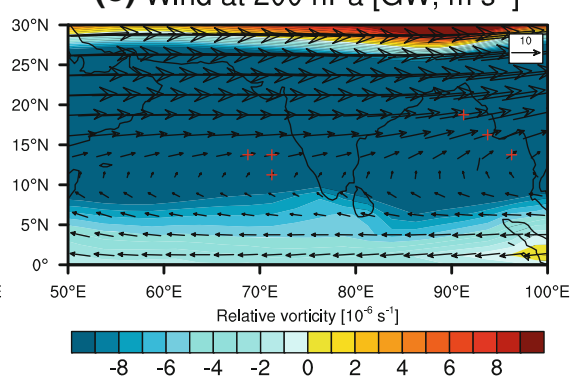

(h) Vert. wind shear [GW, $\mathrm{m} \mathrm{s}^{-1}$ ]

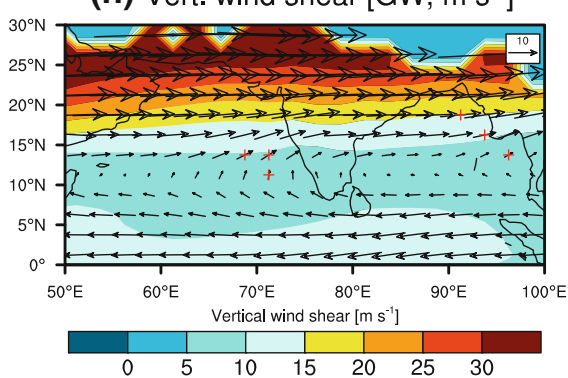

(c) Wind at $850 \mathrm{hPa}$ [GW-PD, $\mathrm{m} \mathrm{s}^{-1}$ ]

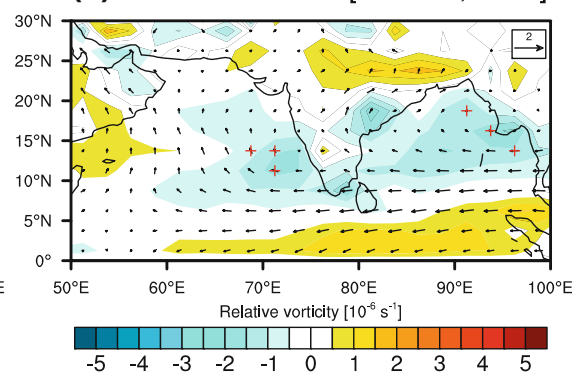

(f) Wind at $200 \mathrm{hPa}$ [GW-PD, $\mathrm{m} \mathrm{s}^{-1}$ ]

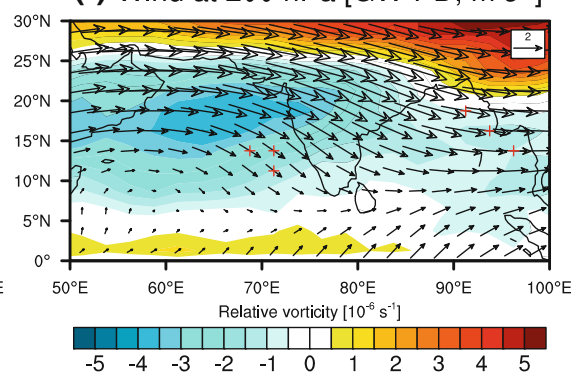

(i) Vert. wind shear [GW-PD, $\mathrm{m} \mathrm{s}^{-1}$ ]

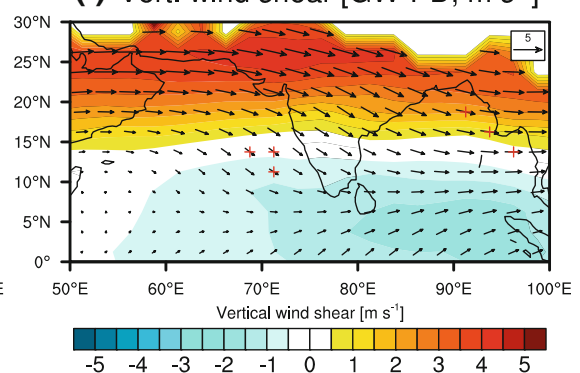

Fig. 11 Maps of ensemble mean of April-May mean winds $\left(\mathrm{m} \mathrm{s}^{-1}\right.$, arrows) and relative vorticity at $850 \mathrm{hPa}\left(10^{-6} \mathrm{~s}^{-1}\right.$, shaded $)$ for a present-day simulations (PD), b future projections (GW), and c projected future changes (GW-PD). d-f As in a-c, but for $200 \mathrm{hPa}$ large-scale winds and relative vorticity. $\mathbf{g}-\mathbf{i}$ As in $\mathbf{a}-\mathbf{c}$, but for vertical

seen in both the present-day predictions and future projections; however, models tend to generate TCs at more intense vertical wind shear compared with observations. The mean vertical wind shears for the observations, present-day simulations, and future projections are 13.1, 13.8, and $14.2 \mathrm{~m} \mathrm{~s}^{-1}$, respectively; however, the future change is not statistically significant at the $90 \%$ level (Welch's $t$ test). The simulated vertical wind shear in the pre-monsoon season exceeds $15 \mathrm{~m} \mathrm{~s}^{-1}$ north of $17^{\circ} \mathrm{N}$ in the present-day simulations (Fig. 11g), and projected future changes show a marked increase in vertical wind shear of about $1.0-3.0 \mathrm{~m} \mathrm{~s}^{-1}$ in the region (Fig. 11i), indicating that the increase in vertical shear may prohibit TC genesis. However, marked TGF reduction is also evident south of $15^{\circ} \mathrm{N}$ in the ARB, where the projected future change in vertical wind shear is small. Overall, the influence of vertical wind shear on the projected changes in TGF is unclear. wind shear $\left(\mathrm{m} \mathrm{s}^{-1}\right.$, arrows) and its magnitude $\left(\mathrm{m} \mathrm{s}^{-1}\right.$, shaded). The plus symbols indicate that the TGF change in the grid cell is statistically significant and robust among the ensemble projections shown in Fig. 9a

Figure 13 shows ensemble mean spatial distributions of the large-scale parameters during the peak-monsoon season of June-August. In contrast to the pre-monsoon season, none of the spatial patterns of the large-scale parameters is correlated with that of TGF (Fig. 9b). However, the large-scale parameters $S_{\mathrm{a}}, V_{\text {pot }}$, and $V_{\mathrm{s}}$ show changes that favour TC genesis in the regions of marked increase in TGF. Figure 14 shows the large-scale circulation in the peak-monsoon season. Intense low-level westerly jets (Fig. 14g, h) and upperlevel easterly winds (Fig. 14d, e) develop throughout the tropics, resulting in large vertical easterly wind shear (greater than $20 \mathrm{~m} \mathrm{~s}^{-1}$ ), and leading in turn to inactive TC genesis occurrence in most of the tropics. Although the models have biases of generating more TCs compared with observations (Fig. 8), simulated/projected TCs formed near the coastline north of $17.5^{\circ} \mathrm{N}$ and poleward of the low-level jet's axis (figure not shown) where climatological mean vertical wind shear is relatively weak (about less than 
Fig. 12 a Probability and b cumulative distributions of TC genesis frequency as a function of monthly mean vertical wind shear $\left(\mathrm{m} \mathrm{s}^{-1}\right)$ according to observations (green), present-day ensemble simulations (blue), and future ensemble projections $(\mathrm{red})$. The JRA-25 is used for the observed vertical wind shear
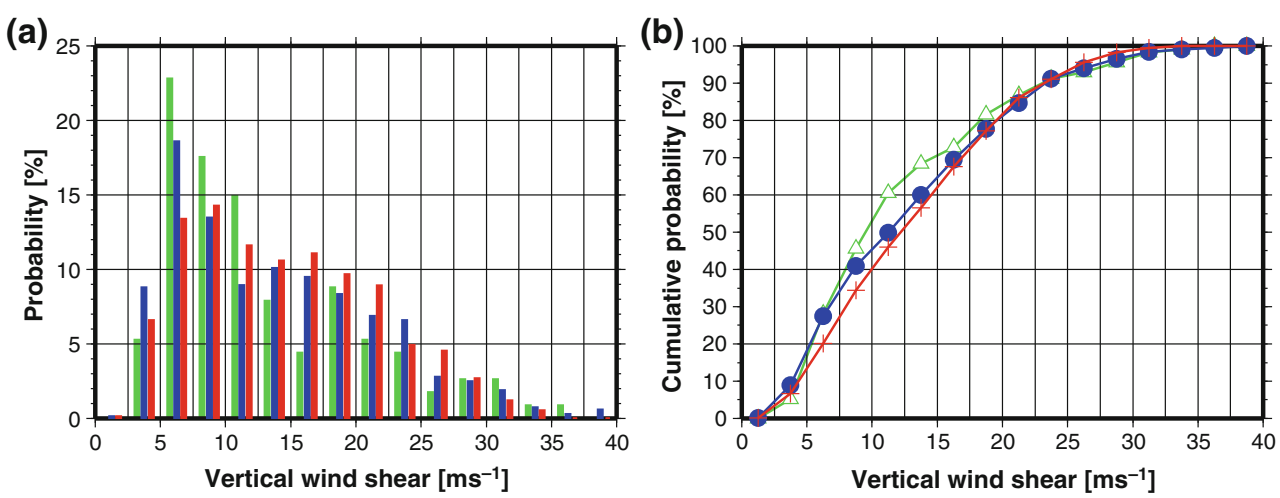

$15 \mathrm{~m} \mathrm{~s}^{-1}$ ). The future changes show marked weakening of large-scale circulations, including low-level westerly flows (Fig. 14c) and upper-level easterly flows (Fig. 14f), leading in turn to a reduction in vertical wind shear (Fig. 14i). Above all, the reduction in vertical wind shear may be one of the major factors responsible for the projected future increases in TGF in the peak-monsoon season. However, it is still difficult to assess the quantitative contributions of vertical wind shear to the TGF changes. For example, the regions showing a marked projected increase in TGF in the BOB still show large vertical wind shear of greater than $15 \mathrm{~m} \mathrm{~s}^{-1}$ even in the future environment (Fig. 14h). The reason why the models tend to generate TCs during the peak-season is not clear so far. After monitoring simulated/projected TCs individually, it turned out that the majority are short-lived and small-scale TCs formed from small-scale disturbances. Further analysis is needed to address why those small-scale TCs can survive under the strong vertical wind shear environment.

Figure 15 shows large-scale parameters during the postmonsoon season of October-December. Thermodynamic parameters $\left(S_{\mathrm{a}}, \mathrm{RH}\right.$, and $\left.V_{\text {pot }}\right)$ are well correlated with the TGF changes. These results indicate that future changes in thermodynamic factors may be of primary importance in determining future changes in TGF over the post-monsoon season. The dynamical parameters $\eta_{850}$ and $\omega_{500}$ are also strongly correlated with the TGF changes. In contrast, vertical wind shear yields a lower correlation coefficient.

Figure 16 shows mean large-scale circulations in the post-monsoon season. The spatial pattern in this season resembles that in the pre-monsoon season (Fig. 11); however, large-scale flows within the upper troposphere change less than in the pre-monsoon season (Fig. 16f), resulting in less changes in the vertical wind shear (Fig. 16i). Vertical wind shear (Fig. 16i) is projected to increase by $1.0-2.0 \mathrm{~m} \mathrm{~s}^{-1}$ north of $20^{\circ} \mathrm{N}$ in the ARB, where TGF shows a marked increase. In contrast, the vertical wind shear does not change in the region between $10^{\circ}$ and $15^{\circ} \mathrm{N}$ in the BOB, where TGF is projected to decrease markedly. These inconsistent results indicate that the changes in vertical shear do not account for the spatial contrast in TGF change between the ARB and BOB in the post-monsoon season. However, we still need to explain the differences in post- and pre-monsoon spatial patterns of future changes in TGF, given that the large-scale parameters do not show these differences. The lack of consistency in the behaviour of the large-scale parameters and TGF, together with the low correlation coefficients between them, makes it difficult to identify the relative contribution of each factor to the spatial distribution of TGF.

Throughout the year, thermodynamic parameters $S_{\mathrm{a}}$, $\mathrm{RH}$, and $V_{\text {pot }}$ tend to show larger increases in the ARB than in the BOB. As indicated by Murakami et al. (2012a), the spatial distributions of the thermodynamic parameters $\mathrm{RH}$ and $V_{\text {pot }}$ correspond to the distribution of $S_{\mathrm{a}}$; i.e., the locations where $S_{\mathrm{a}}$ shows a marked increase also show large increases in RH and $V_{\text {pot }}$. An increase in local SST anomalies in the ARB appears to result in an increase in latent heat flux from the ocean surface, resulting in moisture supply to the lower troposphere, increased convective activity, and enhanced local TC activity. Xie et al. (2010) examined why the prescribed future SST anomaly shows greater warming in the ARB, and proposed that in the eastern tropical Indian Ocean, an easterly wind anomaly results in shoaling of the thermocline in the east, helping to cool SST there via upwelling. In contrast, warm SST is transported to the west of NIO. This pattern of SST anomalies is indicative of Bjerknes feedback and resembles the Indian Ocean dipole (Saji et al. 1999).

The spatial pattern of future change in $\omega_{500}$ is similar to that in $S_{\mathrm{a}}$, indicating that local enhancement in convective activity occurs where SST increases by a larger amount than in surrounded regions (Sugi et al. 2009). Projected subsidence anomaly over the BOB is also seen over the whole year. The projected enhancement of upward motion in the ARB may induce a subsidence anomaly over the BOB due to a local overturning circulation, leading in turn to the suppression of convection, a dry air depression, and TC inactivity in the BOB. The large-scale flows are also projected to weaken throughout the year in the future, as 
(a) $\delta \mathrm{S}_{\mathrm{a}}[\mathrm{K}]$

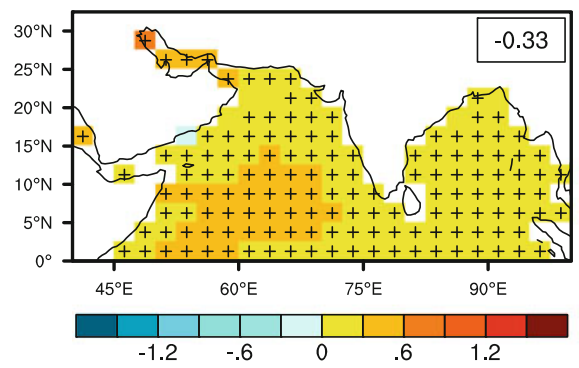

(d) $-\delta \chi\left[10^{2} \mathrm{~Pa}\right]$

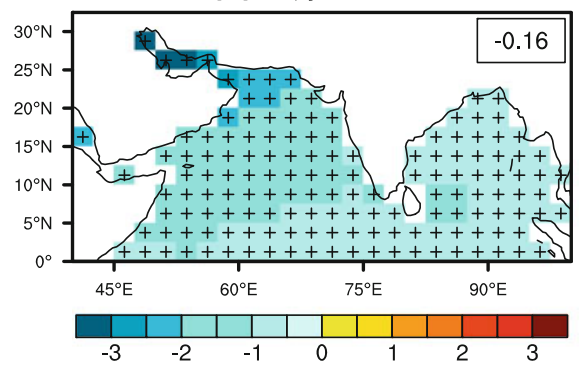

(f) $\delta \eta_{850}\left[10^{-6} \mathrm{~s}^{-1}\right]$

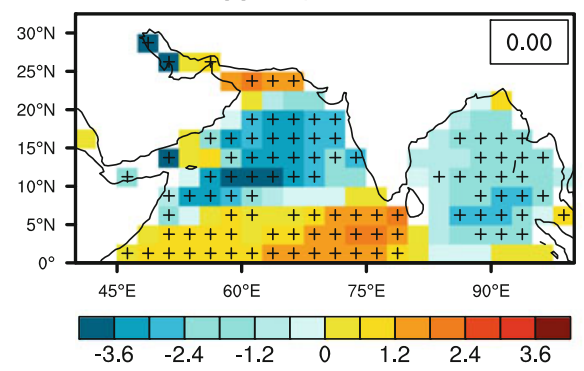

(i) $-\delta \omega_{500}\left[10^{-2} \mathrm{~Pa} \mathrm{~s}^{-1}\right]$

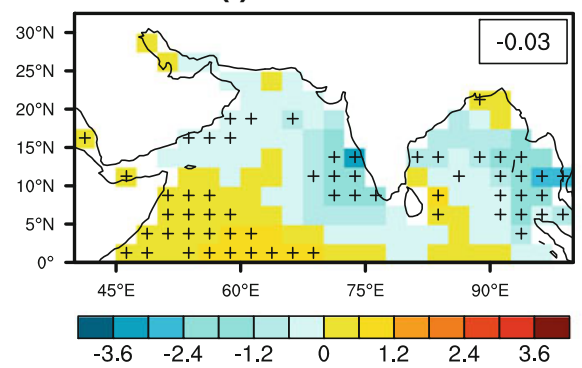

(b) $\delta \mathrm{RH}[\%]$

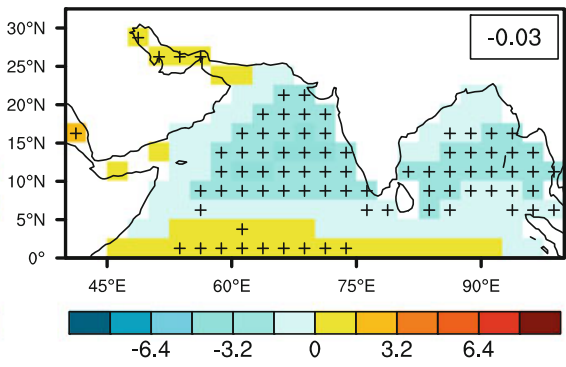

(e) $-\delta \Gamma_{\mathrm{d}}[\mathrm{K}]$

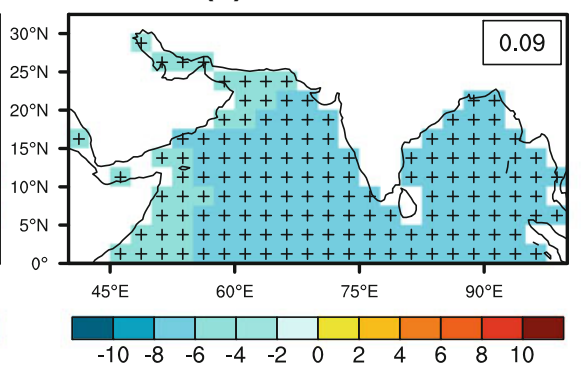

(g) $-\delta \mathrm{V}_{\mathrm{s}}\left[\mathrm{m} \mathrm{s}^{-1}\right]$

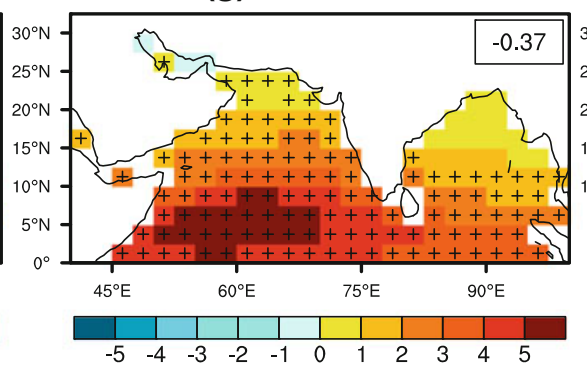

(j) $\delta \mathrm{D}\left[10^{-10} \mathrm{~s}^{-2}\right]$

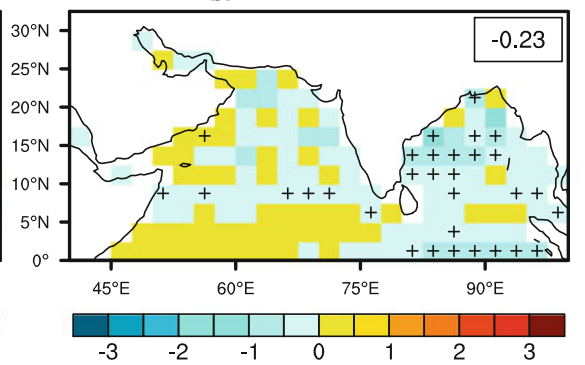

(c) $\delta \mathrm{V}_{\text {pot }}\left[\mathrm{m} \mathrm{s}^{-1}\right]$

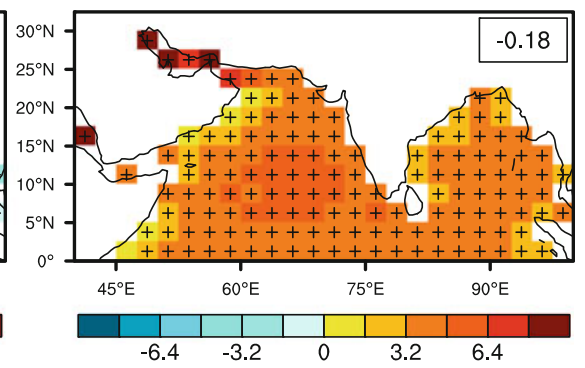

(h) $-\delta \mathrm{V}_{\mathrm{zs}}\left[\mathrm{m} \mathrm{s}^{-1}\right]$

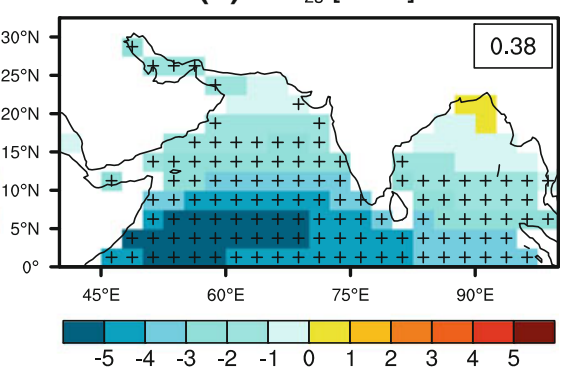

Fig. 13 As in Fig. 10, but for the seasonal mean of June-August

reported previously using different models (e.g., Kitoh et al. 1997; Douville et al. 2000; Stephenson et al. 2001; Tanaka et al. 2004; Ueda et al. 2006; Kripalani et al. 2007; Cherchi et al. 2011; Krishnan et al. 2012). Previous studies have discussed the mechanisms that underlie the weakening of large-scale circulation. For example, Kitoh et al. (1997) suggests that this weakening is due to a northward shift of the monsoon circulation, and Ueda et al. (2006) suggests that the decrease in meridional thermal gradient (MTG) may contribute to the weakening of circulation. Other studies further suggest that an increase in atmospheric static stability could cause the weakening of circulation (Knutson and Manabe 1995; Sugi et al. 2002, 2012). In any event, the models project a future decrease in large-scale circulations, leading to decreases in vertical wind shear in the tropics, which may be partly responsible for the projected TGF changes in this study.

Evan et al. (2011) recently hypothesized that the recently observed increase in the intensity of pre-monsoon TCs in the ARB is a consequence of a decreasing trend in the vertical wind shear. The authors related this decreasing trend in vertical wind shear to the increase in atmospheric 
(a) Wind at $850 \mathrm{hPa}\left[\mathrm{PD}, \mathrm{m} \mathrm{s}^{-1}\right]$

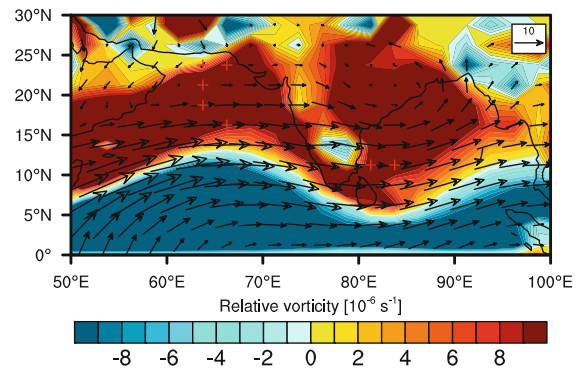

(d) Wind at $200 \mathrm{hPa}\left[\mathrm{PD}, \mathrm{m} \mathrm{s}^{-1}\right]$

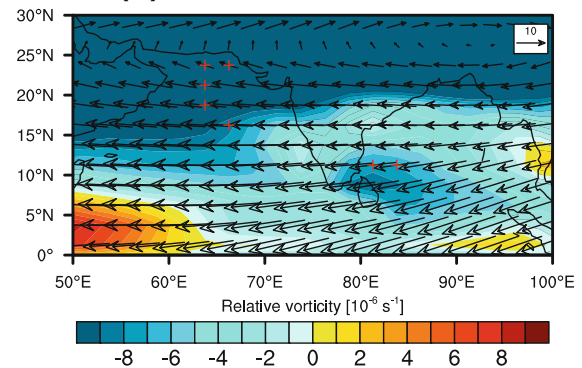

(g) Vert. wind shear [PD, $\left.\mathrm{m} \mathrm{s}^{-1}\right]$

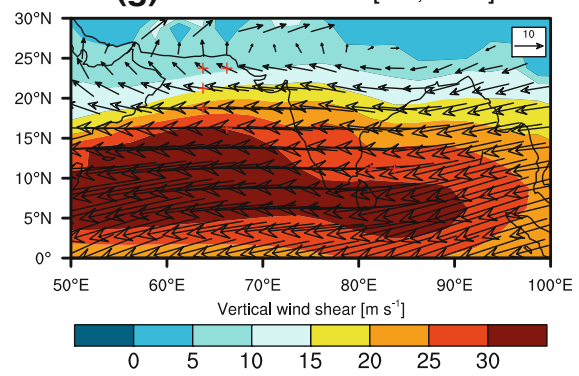

(b) Wind at $850 \mathrm{hPa}\left[\mathrm{GW}, \mathrm{m} \mathrm{s}^{-1}\right]$

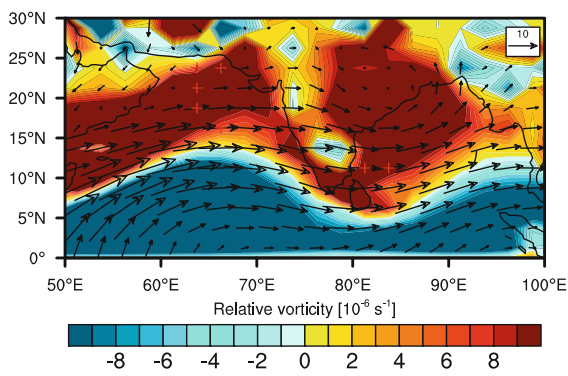

(e) Wind at $200 \mathrm{hPa}$ [GW, $\left.\mathrm{m} \mathrm{s}^{-1}\right]$

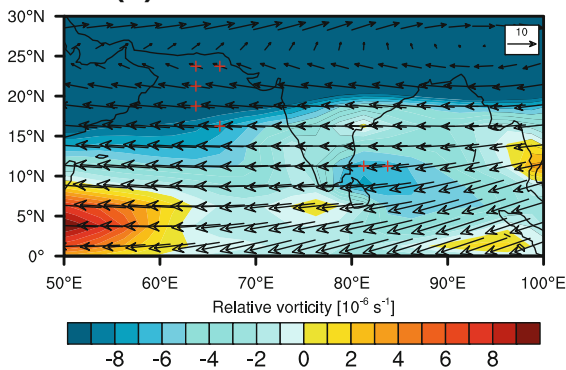

(h) Vert. wind shear [GW, $\left.\mathrm{m} \mathrm{s}^{-1}\right]$

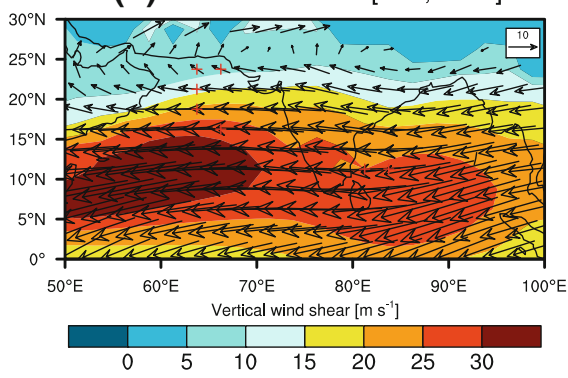

(c) Wind at $850 \mathrm{hPa}$ [GW-PD, $\mathrm{m} \mathrm{s}^{-1}$ ]

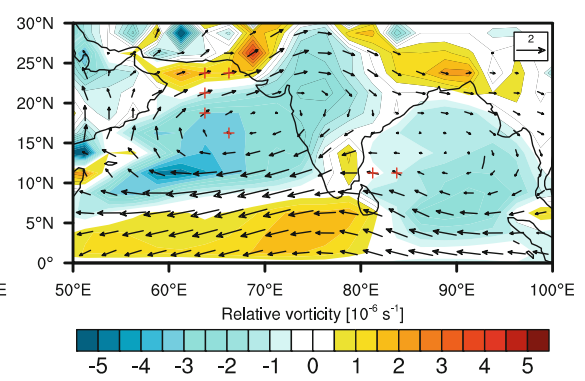

(f) Wind at $200 \mathrm{hPa}$ [GW-PD, $\mathrm{m} \mathrm{s}^{-1}$ ]

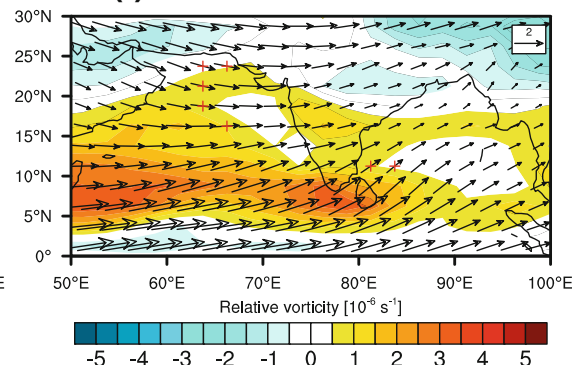

(i) Vert. wind shear [GW-PD, $\mathrm{m} \mathrm{s}^{-1}$ ]

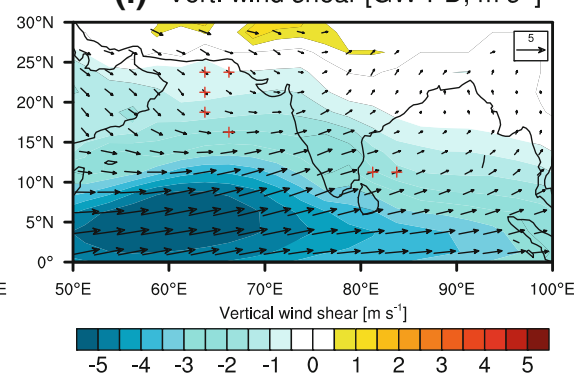

Fig. 14 As in Fig. 11, but for the seasonal mean of June-August

brown clouds. Brown clouds are layers of air pollution consisting of aerosols such as black carbon, which lead both to atmospheric warming by solar radiation absorption and solar radiation reduction at the surface (i.e., stabilization of the troposphere; Ramanathan et al. 2005). The reduction in solar radiation at the surface also induces a weakening of meridional SST gradients in the Indian Ocean, leading in turn to weakening of large-scale circulation and vertical wind shear (Evan et al. 2011). Although the present study focuses on possible future changes, our future projections are partly consistent with the findings of Evan et al. (2011): weakening of vertical wind shear with increases in black carbon in the ARB. In our future projections, we prescribed aerosols computed by MRI-ESM1 in both the present-day and future projections, in which black carbon increases in the future in the ARB (figure not shown). However, the prescribed future changes in SST show larger warming in the ARB (Fig. 1), indicating increases in meridional SST gradients in the Indian Ocean. Our experiments have not considered coupled atmosphereocean interactions, so that it would be worthwhile to more fully explore the effect of black carbon on SST and large-scale changes using a coupled ocean-atmosphere model. It should also be noted that the high correlation reported by Evan et al. (2011) is between vertical wind shear and TC intensity (not TC number). Evan and Camargo (2011) report that year-to-year variations in mean vertical shear are not well correlated with those of genesis potential index (GPI) between 1950 and 2005 in the ARB, GPI is well correlated with relative humidity and low-level vorticity over this period. This result suggests that other dynamical and thermodynamic factors are also responsible for the variations in TC genesis frequency over the region.

\section{Summary}

The 20- and 60-km mesh MRI-AGCMs (v3.2 and v3.1) were used to perform ensemble simulations of the presentday (1979-2003, control) and the end of twenty-first century (2075-2099) climates under the IPCC A1B scenario to 
(a) $\delta S_{a}[K]$

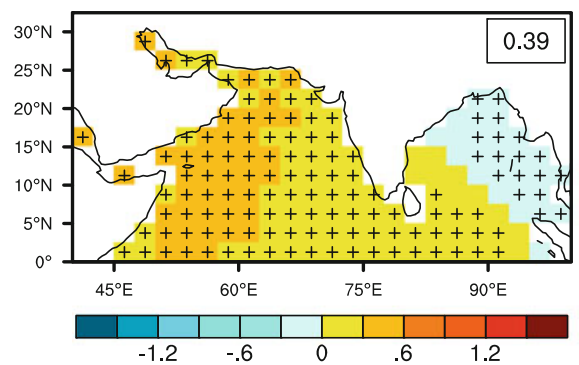

(d) $-\delta \chi\left[10^{2} \mathrm{~Pa}\right]$

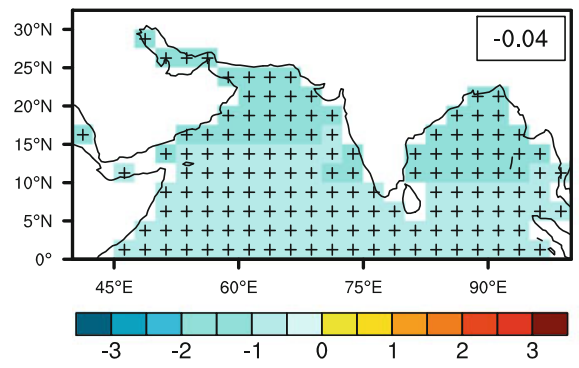

(f) $\delta \eta_{850}\left[10^{-6} s^{-1}\right]$

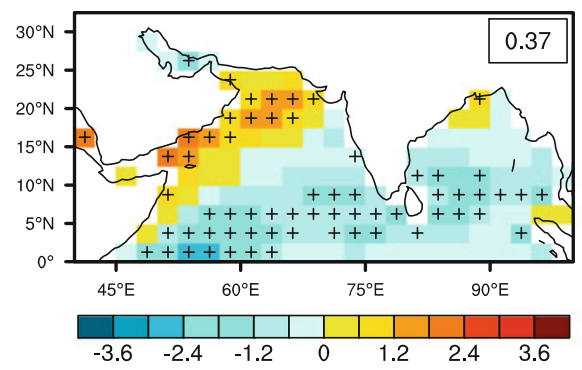

(i) $-\delta \omega_{500}\left[10^{-2} \mathrm{~Pa} \mathrm{~s}^{-1}\right]$

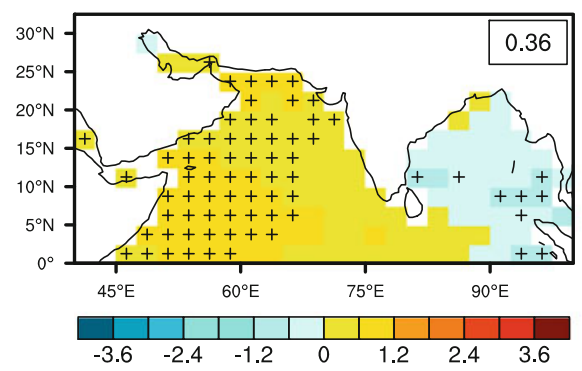

(b) $\delta \mathrm{RH}[\%]$

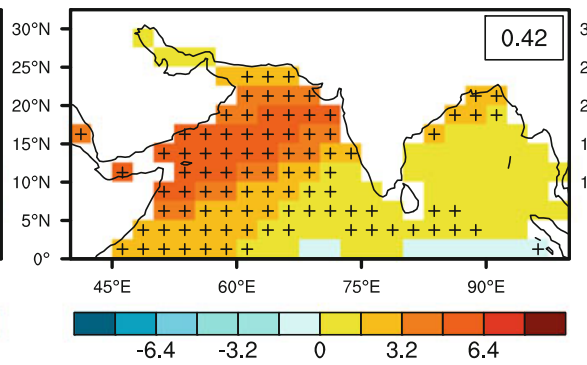

(e) $-\delta \Gamma_{\mathrm{d}}[\mathrm{K}]$

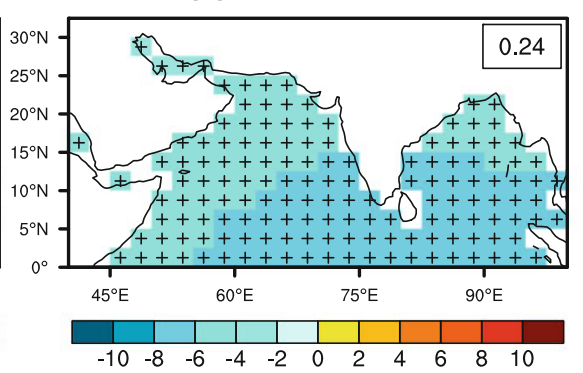

(g) $-\delta \mathrm{V}_{\mathrm{s}}\left[\mathrm{m} \mathrm{s}^{-1}\right]$

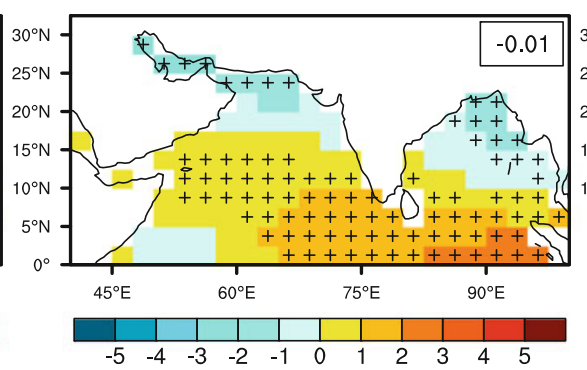

(j) $\delta \mathrm{D}\left[10^{-10} \mathrm{~s}^{-2}\right]$

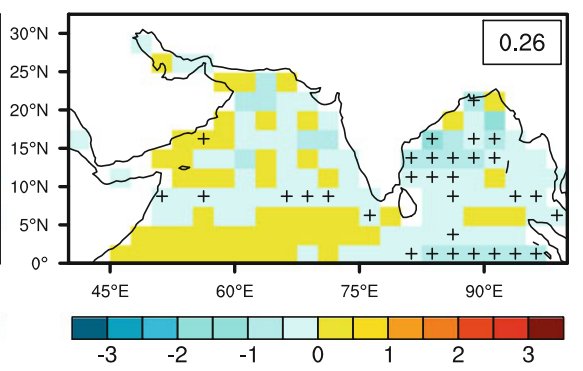

(c) $\delta \mathrm{V}_{\text {pot }}\left[\mathrm{m} \mathrm{s}^{-1}\right]$

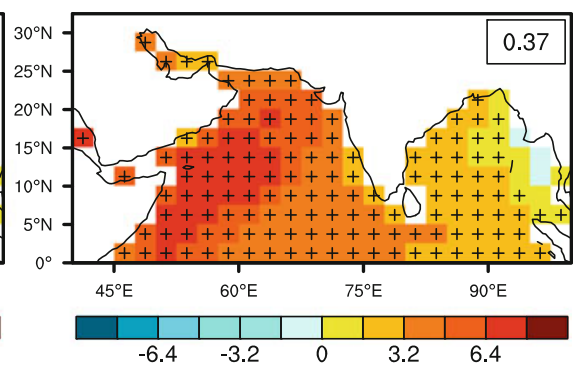

Fig. 15 As in Fig. 10, but for the seasonal mean of October-December

investigate future changes in tropical cyclone (TC) activity in the North Indian Ocean (NIO). The simulations were conducted using three different cumulus convection schemes (the Yoshimura, Kain-Fritsch, and ArakawaSchubert schemes). Future sea surface temperatures (SSTs) were prescribed either as the ensemble mean of 18 CMIP3 models or as one of three different SST spatial patterns determined by a cluster analysis of the CMIP3 models.

The control simulations reveal that all models show a reasonable spatial distribution of TC frequency (TCF) over the NIO, with peaks in the Bay of Bengal (BOB) and Arabian Sea (ARB). However, some models simulate higher TCF in the ARB than in the BOB. Regarding temporal variations in TC genesis number, the model simulations show no skill in reproducing interannual variations in TC genesis number, except for one of the 20-km-mesh model simulations. Simulated seasonal variations in TC genesis number appear to capture observed variations to some degree, including peaks during May-June and October-November. 
(a) Wind at $850 \mathrm{hPa}\left[\mathrm{PD}, \mathrm{m} \mathrm{s}^{-1}\right]$

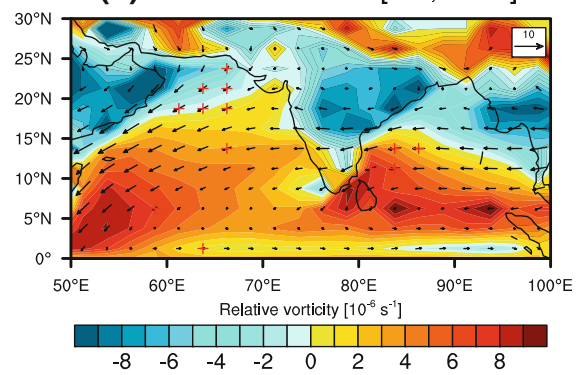

(d) Wind at $200 \mathrm{hPa}\left[\mathrm{PD}, \mathrm{m} \mathrm{s}^{-1}\right]$

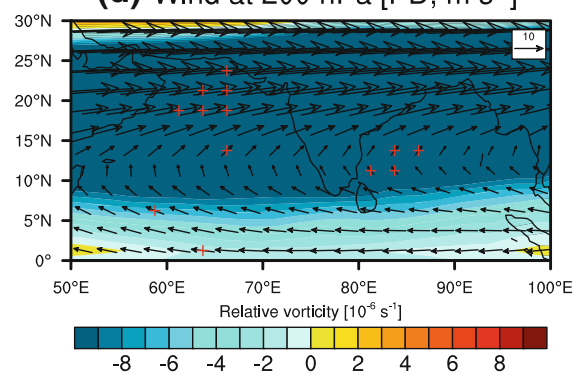

(g) Vert. wind shear [PD, $\left.\mathrm{m} \mathrm{s}^{-1}\right]$

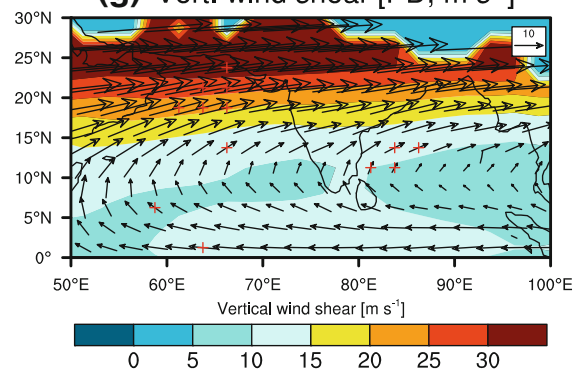

(b) Wind at $850 \mathrm{hPa}$ [GW, $\mathrm{m} \mathrm{s}^{-1}$ ]

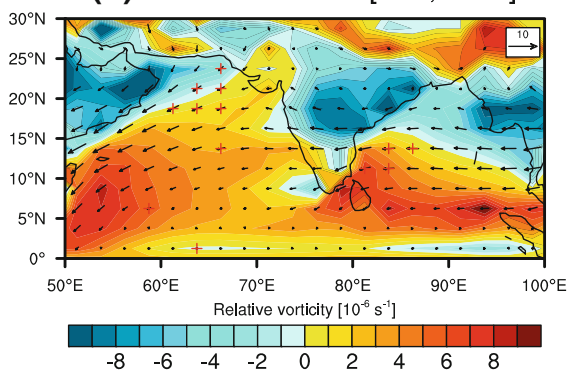

(e) Wind at $200 \mathrm{hPa}$ [GW, $\mathrm{m} \mathrm{s}^{-1}$ ]

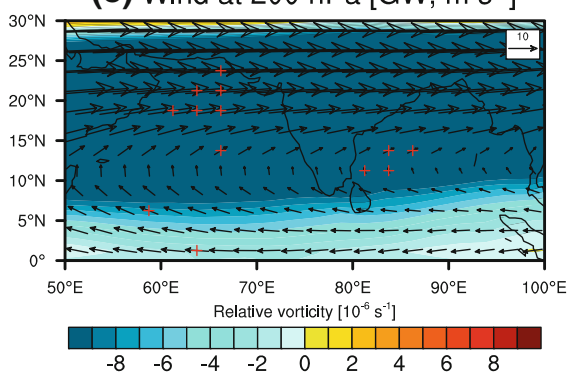

(h) Vert. wind shear [GW, $\left.\mathrm{m} \mathrm{s}^{-1}\right]$

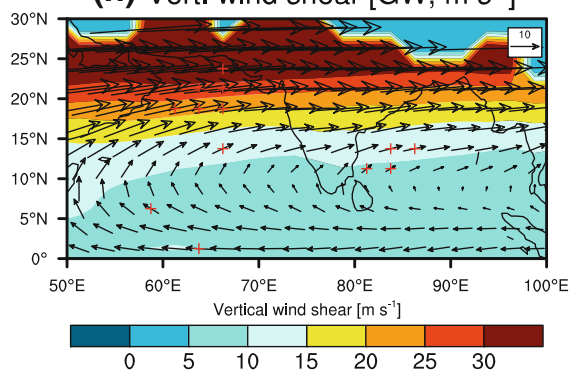

(c) Wind at $850 \mathrm{hPa}\left[\mathrm{GW}-\mathrm{PD}, \mathrm{m} \mathrm{s}^{-1}\right]$

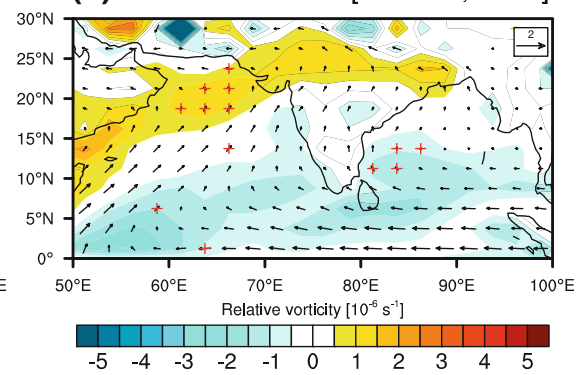

(f) Wind at $200 \mathrm{hPa}$ [GW-PD, $\mathrm{m} \mathrm{s}^{-1}$ ]

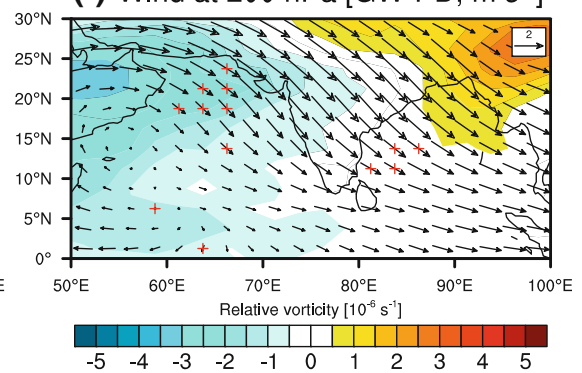

(i) Vert. wind shear [GW-PD, $\mathrm{m} \mathrm{s}^{-1}$ ]

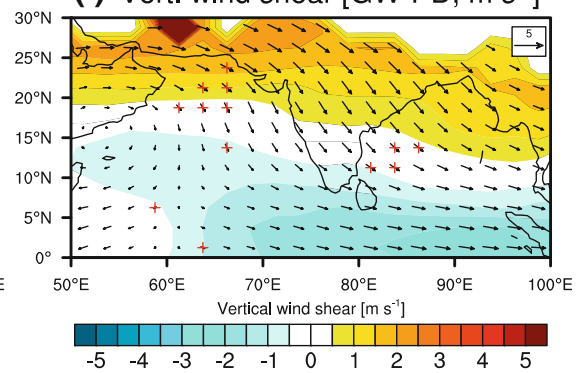

Fig. 16 As in Fig. 11, but for the seasonal mean of October-December

Projected future changes in TC number are not statistically significant by the ensemble experiments in the NIO; however, most of the experiments project a future increase (decrease) in TCF in the ARB (BOB). TC genesis frequency (TGF) was found to be the main factor responsible for future changes in TCF. An analysis of TCF changes indicates that projected future changes in TC genesis contribute about 62 and $76 \%$ to the total TCF changes in the regions with marked TCF changes in the ARB and BOB, respectively.

Changes in dynamical and thermodynamic large-scale parameters were investigated to better identify those factors responsible for the projected future changes in TC genesis frequency, revealing a seasonal dependency of the relative importance of thermodynamic factors (e.g., SST anomaly, relative humidity at $700 \mathrm{hPa}$, and the maximum potential intensity) and dynamical parameters (e.g., vertical wind shear, low-level vorticity, and mid-level vertical p-velocity).

In the pre-monsoon season of April-May, TGF is projected to decrease in both the ARB and BOB. Dynamical large-scale parameters, especially low-level vorticity and vertical wind shear, appear to be the major factors influencing the TGF change. In contrast, TGF is projected to increase in both the ARB and BOB in the peak-monsoon season of June-August. The large-scale parameters responsible for the projected increases in TGF appear to be SST anomaly, maximum potential intensity, and vertical wind shear. The decrease in low-level vorticity during the pre-monsoon season, as well as the reduction in vertical wind shear in both the pre- and peak-monsoon seasons, is attributed to the weakening of large-scale circulation in both the lower and upper troposphere. In the post-monsoon season of October-December, projected future changes in TGF show a marked east-west contrast: a decrease in TGF in the $\mathrm{BOB}$ and an increase in TGF in the ARB. The thermodynamic parameters of SST anomaly, relative humidity, and maximum potential intensity show high spatial correlations with the TGF changes, indicating that future changes in thermodynamic factors may be of primary importance in determining future changes in TGF during the post-monsoon season. 
We should add a caveat that cluster SSTs are set based on the spatial pattern of all-tropical SST; consequently, the results may vary if the cluster SSTs were based on the NIO spatial pattern. Additional SST ensemble experiments may be needed to reduce these uncertainties. Improvements to the present-day simulation, especially the skill regarding interannual variation in TC genesis number, are needed for reliable future projections. It is also a remaining question why projected future changes in TGF differ between the pre- and post-monsoon seasons despite the similar future changes in large-scale parameters. Further analyses are needed for assessing future changes in TC activity.

Acknowledgments This work was conducted under the framework of the "Projection of the Change in Future Weather Extremes using Super-High-Resolution Atmospheric Models" project supported by the KAKUSHIN programme of the Ministry of Education, Culture, Sports, Science, and Technology (MEXT) of Japan. Calculations were performed on the Earth Simulator. This is the International Pacific Research Center publication no. 891 and School of Ocean and Earth Science and Technology publication no. 8683.

Open Access This article is distributed under the terms of the Creative Commons Attribution License which permits any use, distribution, and reproduction in any medium, provided the original author(s) and the source are credited.

\section{References}

Arakawa A, Schubert WH (1974) Interaction of cumulus cloud ensemble with the large-scale environment. Part I. J Atmos Sci 31:674-701

Bell GD (2003) Atlantic hurricane season [in "State of the Climate in 2002"] Bull. Am Meteorol Soc 84:S19-S26

Bengtsson L, Botzet M, Esch M (1996) Will greenhouse gas-induced warming over the next 50 years lead to higher frequency and greater intensity of hurricanes? Tellus 48A:57-73

Bister M, Emanuel KA (1998) Dissipative heating and hurricane intensity. Meteorol Atmos Phys 52:233-240

Camargo SJ, Emanuel KA, Sobel AH (2007) Use of a genesis potential index to diagnose ENSO effects on tropical cyclone genesis. J Clim 20:4819-4834

Cherchi A, Alessandri A, Masina S, Navarra A (2011) Effects of increased $\mathrm{CO}_{2}$ on monsoons. Clim Dyn 37:83-101. doi: 10.1007/s00382-010-0801-7

Diamond HJ, Trewin BC (2011) [Tropics] Tropical cyclones [in "State of the Climate in 2010"]. Bull Am Meteorol Soc 92(6):S114-S131

Douville H, Royer JF, Polcher J, Cox P, Gedney N, Stephenson DB, Valdes PJ (2000) Impact of $\mathrm{CO}_{2}$ doubling on the Asian summer monsoon: robust versus model-dependent responses. J Meteorol Soc Jpn 78:421-439

Emanuel K (1987) The dependence of hurricane intensity on climate. Nature 326:483-485

Emanuel K (2008) Hurricanes and global warming. Bull Am Meteorol Soc 89:347-367

Emanuel KA, Nolan DS (2004) Tropical cyclone activity and global climate. Preprints. In: 26th conference on hurricanes and tropical meteorology. American Meteorological Society, Miami, FL, pp 240-241
Evan AT, Camargo SJ (2011) A climatology of Arabian Sea cyclonic storms. J Clim 24:140-158

Evan AT, Kossin JP, Chung CE, Ramanathan V (2011) Arabian Sea tropical cyclones intensified by emissions of black carbon and other aerosols. Nature 479:94-97

Gray WM (1968) Global view of the origin of tropical disturbances and storms. Mon Weather Rev 96:669-700

Kain JS, Fritsch JM (1990) A one-dimensional entraining/detraining plume model and its application in convective parameterization. J Atmos Sci 47:2784-2802

Kain JS, Fritsch JM (1993) Convective parameterization for mesoscale models: the Kain-Fritsch scheme. In: Emanuel KA, Raymond DJ (eds) The representation of cumulus convection in numerical models of the atmosphere. Meteorology Monographs No. 46. American Meteorological Society, pp 165-170

Kitoh A, Yukimoto S, Noda A, Motoi T (1997) Simulated changes in the Asian summer monsoon at times of increased atmospheric $\mathrm{CO}_{2}$. J Meteorol Soc Jpn 75:1019-1031

Knapp KR, Kruk MC, Levinson DH, Diamond HJ, Neumann CJ (2010) The international best track archive for climate stewardship (IB-TrACS). Bull Am Meteorol Soc 91:363-376

Knutson TR, Manabe S (1995) Time-mean response over the tropical Pacific to increased $\mathrm{CO}_{2}$ in a coupled ocean-atmospheric model. J Clim 8:2181-2199

Knutson T, McBride JL, Chan J, Emanuel K, Holland G, Landsea C, Held I, Kossin JP, Srivastava AK, Sugi M (2010) Tropical cyclones and climate change. Nat Geosci 3:157-163

Kripalani RH, Oh JH, Kulkarni A, Sabade SS, Chaudhari HS (2007) South Asian summer monsoon precipitation variability: coupled model simulations and projections under IPCC AR4. Theor Appl Climatol 90:133-159

Krishnan R, Sabin TP, Ayantika DC, Kitoh A, Sugi M, Murakami H, Turner AG, Slingo JM, Radendran K (2012) Will the South Asian monsoon overturning circulation stabilize any further? Clim Dyn. doi:10.1007/s00382-012-1317-0

Landsea CW, Harper BA, Hoarau K, Knaff JA (2006) Can we detect trends in extreme tropical cyclones? Science 313:452-454

Lau K-H, Lau N-C (1990) Observed structure and propagation characteristics of tropical summertime synoptic-scale disturbances. Mon Weather Rev 118:1888-1913

Mizuta R, Oouchi K, Yoshimura H, Noda A, Katayama K, Yukimoto S, Hosaka M, Kusunoki S, Kawai H, Nakagawa M (2006) 20-km-mesh global climate simulations using JMA-GSM model-mean climate states. J Meteorol Soc Jpn 84:165-185

Mizuta R, Yoshimura H, Murakami H, Matsueda M, Endo H, Ose T, Kamiguchi K, Hosaka M, Sugi M, Yukimoto S, Kusunoki S, Kitoh A (2012) Climate simulations using MRI-AGCM with 20-km grid. J Meteorol Soc Jpn 90A:235-260

Murakami H, Mizuta R, Shindo E (2012a) Future changes in tropical cyclone activity projected by multi-physics and multi-SST ensemble experiments using the 60-km-mesh MRI-AGCM. Clim Dyn. doi:10.1007/s00382-011-1223-x

Murakami H, Wang Y, Sugi M, Yoshimura H, Mizuta R, Shindo E, Adachi Y, Yukimoto S, Hosaka M, Kitoh A, Ose T, Kusunoki S (2012b) Future changes in tropical cyclone activity projected by the new high-resolution MRI-AGCM. J Clim 25:3237-3260

Onogi K et al (2007) The JRA-25 reanalysis. J Meteorol Soc Jpn 85:369-432

Ramanathan V et al (2005) Atmospheric brown clouds: impacts on South Asian climate and hydrological cycle. Proc Natl Acad Sci USA 102(15):5326-5333

Randall D, Pan D-M (1993) Implementation of the ArakawaSchubert cumulus parameterization with a prognostic closure. The representation of cumulus convection in numerical models. Meteorol Monogr Am Meteorol Soc 46:137-144 
Rayner NA, Parker DE, Horton EB, Folland CK, Alexander LV, Rowell DP (2003) Global analysis of sea surface temperature, sea ice, and night marine air temperature since the late nineteenth century. J Geophys Res 108:4407

Saji NH, Goswami BN, Vinayachandran PN, Yamagata T (1999) A dipole mode in the tropical Indian Ocean. Nature 401:360-363

Singh OP, Khan TMA, Rahman MS (2000) Changes in the frequency of tropical cyclones over the North Indian Ocean. Meteorol Atmos Phys 75:11-20

Solomon SD, Qin MM, Marquis M, Averyt K, Tignor MMB, Miller L Jr, Chen Z (eds) (2007) Climate change 2007: the physical science basis. Contribution of working group I to the fourth assessment report of the Intergovernmental Panel on Climate Change. Cambridge University Press, 996 pp

Stephenson DB, Douville H, Rupa Kumar K (2001) Searching for a fingerprint of global warming in the Asian summer monsoon. Mausum 52:213-220

Sugi M, Noda A, Sato N (2002) Influence of global warming on tropical cyclone climatology: an experiment with the JMA Global Model. J Meteorol Soc Jpn 80:249-272

Sugi M, Murakami H, Yoshimura J (2009) A reduction in global tropical cyclone frequency due to global warming. SOLA 5:164-167

Sugi M, Murakami H, Yoshimura J (2012) On the mechanism of tropical cyclone frequency changes due to global warming. J Meteorol Soc Jpn 90A:399-410

Tanaka TY, Orio K, Sekiyama T, Shibata K, Chiba M, Tanaka H (2003) MASINGAR, a global tropospheric aerosol chemical transport model coupled with MRI/JMA98 GCM: model description. Pap Meteorol Geophys 53:119-138

Tanaka HL, Ishizaki N, Kitoh A (2004) Trend and interannual variability of Walker, monsoon and Hadley circulations defined by velocity potential in the upper troposphere. Tellus 50A: 250-269

Ueda H, Iwai A, Kuwako K, Hori ME (2006) Impact of anthropogenic forcing on the Asian summer monsoon as simulated by eight GCMs. Geophys Res Lett 33:L06703. doi:10.1029/2005 GL025336

Unisys (2012) Unisys weather hurricane tropical data. Available online at http://weather.unisys.com/hurricane/

Xie S-P, Deser C, Vecchi GA, Ma J, Teng H, Wittenberg AT (2010) Global warming pattern formation: sea surface temperature and rainfall. J Clim 23:966-986

Yukimoto S et al. (2011) Meteorological Research Institute-Earth System Model v1 (MRI-ESM1)—model description. Technical report Meteorological Research Institute 64, $88 \mathrm{pp}$. Available at http://www.mri-jma.go.jp/Publish/Technical/DATA/VOL_64/index. $\mathrm{html}$

Zhao M, Held IM (2012) TC-permitting GCM simulations of hurricane frequency response to sea surface temperature anomalies projected for the late-twenty-first century. J Clim 25: 2995-3009

Zhao M, Held IM, Lin S-J, Vecchi GA (2009) Simulations of global hurricane climatology, interannual variability, and response to global warming using a $50 \mathrm{~km}$ resolution GCM. J Clim 22: 6653-6678 